\title{
Evaluation on Conductive and Displacement Current Along Towers Struck by Lightning Return Strokes Based on Exact Estimation in Self- Inductance, Resistance and Capacitance of Down-Conductors with High Relative Permeability
}

\author{
Hiroshi Kurita*
}

\section{3-4 Zaimoku-cho, Higashimatsuyama, Saitama, 0355-0016, Japan}

\begin{abstract}
The calculation methods on the internal self-inductance and equivalent resistance of conductive cylindrical pipes are explained in consideration of skin effect stems from "Maxwell's equations related to Faraday's law, Ampere's law and Gaussian law" and "electric characteristic within conductors". The calculation results in the internal selfinductance and the equivalent resistance are shown on the conductive cylindrical pipes made from steel with high relative permeability. The potential difference per meter $\varphi_{/ /}$along the activated conductive cylindrical pipes stems from the effects on the external self-inductance, the internal self-inductance and the equivalent resistance is compared each other. In the cases of the thick conductive cylindrical pipes installed for the main down-conductors of high rise towers for example $5 \times 10^{-1} \mathrm{~m}$ in radius, the effects in the internal self-inductance and the equivalent resistance taken into account the skin effect can be neglected compared to the effect in the external self-inductance on the potential rise. In the cases of the thin conductive cylindrical pipes with small radius $5 \times 10^{-3} \mathrm{~m}$ and the lightning return strokes conductive current characterized by low rising frequency $10 / 350 \mu$ s and small peak $1 \mathrm{kA}$, the effects in the internal self-inductance and the equivalent resistance are $20 \%$ and $8 \%$ for the effect in the external self-inductance on peak value of the rising potential, respectively. Single Models (conductive cylindrical pipes $600 \mathrm{~m}$ in length) are proposed for the evaluation.
\end{abstract}

The Models of high rise towers $600 \mathrm{~m}$ in height struck by lightning return strokes are proposed to estimate provisional potential along the Models $\varphi$. The 15 conductive cylindrical pipes $5 \times 10^{-1} \mathrm{~m}$ in radius made from steel are used for down-conductors of the Models. Grounding resistance is given as 1,2 and $5 \Omega$.

The transfer theorem between conductive current $I_{c}$ and displacement current $I_{d}$ is explained based on the Maxwell's equation related to Ampere's law. The Group Models which can calculate the tendencies on the diverging in the displacement current $I_{d}$ and the displacement current density $\vec{j}_{d}$ along the Models of high rise towers struck by lightning return strokes are proposed. A Group Model consists of a cylindrical conductors group and a metallic cylindrical outer coaxial pipe. The provisional potential along Models of high rise towers on each height $\varphi$ is given to the cylindrical conductors groups. The metallic cylindrical outer coaxial pipes are grounded. Radius of the metallic cylindrical outer coaxial pipe is varying. The tendencies on the displacement current $I_{d}$ and the displacement current density $\vec{j}_{d}$ between the cylindrical conductors groups and the metallic cylindrical outer coaxial pipes are analyzed. The displacement current $\mathrm{I}_{d}$ and the displacement current density $\vec{j}_{d}$ are stems from the surface electric field $\vec{E}$ on the outer side in the cylindrical conductors groups evaluated with the Maxwell's equations related to Gaussian law. The electric field $\overrightarrow{\mathrm{E}}$ is owing to "provisional potential along Models of high rise towers evaluated on each height $\varphi$ " and "capacitive coupling on Group Models between cylindrical conductors groups and metallic cylindrical outer coaxial pipes which simulates capacitive coupling between the Models of high rise towers on each height and the flat ground".

The experimental tendencies on the deformation in the conductive current waveforms of lightning return strokes along high rise towers $I_{c}$ which have been already measured are introduced. The current peaks $I_{p}$ and rising frequencies $f_{r}$ on the conductive current $I_{c}$ drastically decrease corresponding with rise of evaluation height along the towers. Causes of the experimental results are broadly explained stems from the tendencies on the diverging in the displacement current $I_{d}$ and the displacement current density $\vec{j}_{\mathrm{d}}$ along the Models of high rise towers analyzed with the Group Models.

The typical waveforms on conductive current of lightning return strokes $10 / 350 \mu$ s and $1 / 200 \mu$ s are selected for the evaluation.

Keywords: External self-inductance, internal self-inductance, resistance and capacitance on steel down-conductors of high rise towers, high relative permeability, skin effect, transfer theorem between conductive current and displacement current, Maxwell's equations, conductive current of lightning return strokes $10 / 350 \mu$ s and 1/200 $\mu$ s.

*Address correspondence to these authors at the 23-4 Zaimoku-cho, Higashimatsuyama, Saitama, 0355-0016, Japan;

Tel: 81-493-22-405; E-mail: t3kurita@kxa.biglobe.ne.jp

\section{INTRODUCTION}

The electric field $\overrightarrow{\mathrm{E}}$ and magnetic field $\overrightarrow{\mathrm{B}}$ caused by the conductive current of lightning return strokes along down- 
conductors of structures $I_{c}$ should be precisely evaluated for establishment of accurate lightning parameters $[1,2]$ and protection of persons against those fields $[3,4]$ as well as the conductive current along channels of the lightning return strokes. It is necessary for calculation of the electric field $\overrightarrow{\mathrm{E}}$ and the magnetic field $\overrightarrow{\mathrm{B}}$ to estimate the precise potential $\varphi$ and vector potential $\vec{A}$ on evaluation points [5]. On the other hand, the estimation on the potential along the downconductors $\varphi$ activated by the conductive current of the lightning return strokes $I_{c}$ is instrumental to the protection of persons against electric shocks and the protection of electrical apparatuses against electric breakdowns within and around structures [6-8]. Furthermore, the evaluation on the conductive current along each down-conductor $I_{c}$ owing to the lightning return strokes is important on the way from a lightning point to the several earth termination system or an earth termination system because many down-conductors are installed on large scale structures [7].

The conductive current along the high rise towers $I_{c}$ struck by lightning return strokes [9-12] must be estimated taking into account the diverging on displacement current along the towers $I_{d}$ in order to precisely calculate the electric field $\overrightarrow{\mathrm{E}}$ and magnetic field $\overrightarrow{\mathrm{B}}$ originated from the towers. The diverging on displacement current $I_{d}$ along the conductive current $I_{c}$ is affected by the time dependence of surface electric field $\overrightarrow{\mathrm{E}}$ along the towers. And, the surface electric field $\overrightarrow{\mathrm{E}}$ is influenced by "configurations and locations on struck towers, lightning return strokes and surroundings (the flat ground, structures, mountains, and hills etc.)" and "distribution of surface potential on those items $\varphi$ ". Meanwhile, the discussion on the significance in the internal self-inductance and equivalent resistance of downconductors taken into account skin effect is inevitable for calculation on the potential along the towers $\varphi$ as well as the specification on "external self-inductance of downconductors" and "grounding resistance of earth termination system". Since steel is usually used for material on the down-conductors of the towers $[6,7]$, the effects in the internal self-inductance and the equivalent resistance characterized by high relative permeability should be evaluated to be compared with the effect in the external selfinductance on the potential rise along the down-conductors.

On this paper, the internal self-inductance and equivalent resistance of the conductive cylindrical pipes with high relative permeability are evaluated in consideration of skin effect stems from Maxwell's equations, firstly. Secondary, the potential difference per meter along the activated conductive cylindrical pipes $\varphi_{/ 1}$ based on the effects in external self-inductance, internal self-inductance and equivalent resistance is compared each other varying radius of the conductive cylindrical pipes. Furthermore, the tendencies on the diverging in displacement current along Models of high rise towers $I_{d}$ are provisionally evaluated taking into account the conditions on the grounding resistance, self-inductance of down-conductors (conductive cylindrical pipes) and capacitive coupling to the flat grounds in the Models. The provisional displacement current $I_{d}$ is evaluated stems from the provisional surface electric field $\overrightarrow{\mathrm{E}}$ along the Models estimated with Gaussian law and numerical electric field analysis. The surface potential along the Models $\varphi$ is provisionally evaluated for calculation of the provisional surface electric field $\overrightarrow{\mathrm{E}}$. Finally, the reason on the experimental tendencies in the deformation in the conductive current waveforms of lightning return strokes along high rise towers $I_{c}$ which have been already measured is broadly explicated using the calculation results on the tendencies in the diverging of the provisional displacement current along the Models of high rise towers $\mathrm{I}_{\mathrm{d}}$. The typical waveforms on conductive current of lightning return strokes $10 / 350 \mu$ s and $1 / 200 \mu$ s are selected for the evaluation.

\section{FUNDAMENTAL THEORY}

\subsection{Skin Effect}

The Maxwell's equations related to Faraday's law, Gaussian law and Ampere's law are shown in equations (1), (2) and (3), respectively.

$$
\begin{aligned}
& \operatorname{rot} \vec{E}=-\frac{\partial \vec{B}}{\partial t} \\
& \operatorname{div} \vec{E}=\frac{\rho_{v o}}{\varepsilon_{r} \varepsilon_{0}} \\
& \operatorname{rot} \vec{B}=\mu_{r} \mu_{0} \vec{j}_{c}+\frac{\mu_{r} \varepsilon_{r}}{c^{2}} \frac{\partial \vec{E}}{\partial t}
\end{aligned}
$$

, where

$\overrightarrow{\mathrm{E}}$ : Electric field (V/m)

$\overrightarrow{\mathrm{B}}$ : Magnetic field (T)

$\rho_{\mathrm{vo}}$ : Volume charge density $\left(\mathrm{C} / \mathrm{m}^{3}\right)$

$\overrightarrow{\mathrm{j}}_{\mathrm{c}}$ : Conductive current density $\left(\mathrm{A} / \mathrm{m}^{2}\right)$

$\varepsilon_{0}$ : Permittivity in vacuum $(\mathrm{F} / \mathrm{m})$

$\varepsilon_{\mathrm{r}}$ : Relative permittivity, 1 in vacuum

$\mu_{0}$ : Permeability in vacuum $(\mathrm{H} / \mathrm{m})$

$\mu_{\mathrm{r}}$ : Relative permeability, 1 in vacuum

t: Time (second)

c: Light speed $(\mathrm{m} / \mathrm{s})$

Within conductors, there are unique conditions as shown in equations (4) and (5).

$$
\begin{aligned}
& \vec{j}_{c} \gg \varepsilon_{r} \varepsilon_{0} \frac{\partial \vec{E}}{\partial t} \\
& \varepsilon_{r}=\infty
\end{aligned}
$$

As the results, the original Maxwell's equations (3) and (2) are modified into equations (6) and (7) within the conductors, respectively.

$$
\operatorname{rot} \vec{B} \cong \mu_{r} \mu_{0} \vec{j}_{c}
$$

, where

$\mu_{\mathrm{r}}$ : Relative permeability of conductors

$\operatorname{div} \vec{E}=0$

Meanwhile, there is a relation between conductive current density $\overrightarrow{\mathrm{j}}_{\mathrm{c}}$ and electric field $\overrightarrow{\mathrm{E}}$ within the conductors.

$\vec{j}_{c}=\sigma \vec{E}$

, where 


\section{$\sigma:$ Conductivity $(\mathrm{S} / \mathrm{m})$}

Equation (9) is able to be derived from the equations (1), (6), (7) and (8) (refer to 7.1 Appendix 1).

$\nabla^{2} \vec{E}=\mu_{r} \mu_{0} \sigma \frac{\partial \vec{E}}{\partial t}$

The solution of the equation (9) is given as shown in equations (10) and (11) on the condition that longitudinal center axes of conductive cylindrical pipes (refer to 3.1.2 (1)) are fixed along vertical $y-a x e s$ of $x-y-z$ Cartesian coordinate system. The vertical electric field $\overrightarrow{\mathrm{E}}$ on the equation (9) has the same direction as the direction on the conductive current density within the conductive cylindrical pipes $\vec{j}_{c}$ as shown in the equation (8). The penetration depth $\delta(t)$ indicated on the equation (11) can be expressed with the angular frequencies $\omega(t)$ at each time on pulse waveforms of current.

$\vec{E}(t, x)=\vec{E}(t, a) e^{-\frac{a-x}{\delta(t)}}$

$\delta(t)=\sqrt{\frac{2}{\mu_{r} \mu_{0} \sigma \omega(t)}}$

, where

$\overrightarrow{\mathrm{E}}(\mathrm{t}, \mathrm{x})$ : Horizontal distribution of vertical electric field within conductive cylindrical pipes $(\mathrm{V} / \mathrm{m})$

$\vec{E}(t, a)$ : Vertical electric field located the most outside within conductive cylindrical pipes $(\mathrm{V} / \mathrm{m})$

$\mathrm{x}$ : One of horizontal axes on $\mathrm{x}-\mathrm{y}-\mathrm{z}$ Cartesian coordinate system

a: Outer radius of conductive cylindrical pipes (m)

The horizontal distribution on the vertical conductive current density within the conductive cylindrical pipes $\vec{j}_{c}(t$, $\mathrm{x})$ is given with the equations (11) and (12) referred to the equations (8) and (10).

$\vec{j}_{c}(t, x)=\vec{j}_{c}(t, a) e^{-\frac{a-x}{\delta(t)}}$

, where

$\vec{j}_{c}(t, x)$ : Horizontal distribution of vertical conductive current density within conductive cylindrical pipes $\left(\mathrm{A} / \mathrm{m}^{2}\right)$

$\vec{j}_{c}(t, a)$ : Vertical conductive current density located the most outside within conductive cylindrical pipes $\left(\mathrm{A} / \mathrm{m}^{2}\right)$

\subsection{Transfer Between Conductive Current and Displacement Current}

Apply "div" to both side of the Maxwell's equation (3) in vacuum. And, adopt a formula of vector analysis (13) to get equation (14).

$\operatorname{divrot} \vec{B}=0$

$\operatorname{div}\left(\vec{j}_{c}+\varepsilon_{0} \frac{\partial \vec{E}}{\partial t}\right)=0$

Furthermore, apply volume integral to both side of the equation (14) and adopt Gaussian theorem of vector analysis to obtain equation (15). $\iint\left(\vec{j}_{c}+\varepsilon_{0} \frac{\partial \vec{E}}{\partial t}\right) \cdot d \vec{S}=0$

, where

$\mathrm{d} \overrightarrow{\mathrm{S}}$ : Areal vector element on integration

The conductive current $I_{c}$ and displacement current $I_{d}$ flowing into a closed area can be transferred each other taking into account the aspects on the formation in the time varying electric field $\vec{E}$ in surfaces of high voltage matter as shown in the equation (15).

\section{CALCULATION METHODS}

\subsection{Modeling}

Single Models $600 \mathrm{~m}$ in length are proposed for the evaluation on "external self-inductance, internal selfinductance and equivalent resistance of conductive cylindrical pipes" and "potential difference per meter along conductive cylindrical pipes $\varphi_{/ 1}$ owing to effects of those factors". And, the Models of high rise towers with height $600 \mathrm{~m}$ struck by lightning return strokes are proposed to estimate provisional potential along the Models $\varphi$. Furthermore, Group Models are proposed for the evaluation on the tendencies in the provisional electric field $\overrightarrow{\mathrm{E}}$, displacement current density $\vec{j}_{d}$ and displacement current $I_{d}$ caused along the Models of high rise towers (refer to Note 1). A Group Model consists of a cylindrical conductors group and a metallic cylindrical outer coaxial pipe. The conductive cylindrical pipes which have the ring width enough thick compared with penetration depth of skin effect $\delta$ are used for the Single Models and the Models of high rise towers.

Note 1: The deformation in the conductive current waveforms of lightning return strokes along Models of high rise towers $I_{c}$ owing to diverging of displacement current along the Models $I_{d}$ isn't exactly taken into account in the calculation of the provisional potential $\varphi$, surface electric field $\vec{E}$, displacement current density $\vec{j}_{\mathrm{d}}$ and displacement current $I_{d}$ on this paper. (refer to 3.9, 5.2 and 6.1).

\subsubsection{Material of Models}

In the cases of the external lightning protection system not isolated from the structures to be protected (refer to Note 2 ), down-conductors are natural component of lightning protection system (refer to Note 3) [6, 7]. The natural component is generally made from the steel characterized by high relative permeability [7]. Typical electrical characteristics of the steel are shown in Table 1. The material indicated on the Table $\mathbf{1}$ is applied for Single Models and Models of high rise towers.

Note 2: External lightning protection system not isolated from the structure to be protected [6]

LPS (Lightning protection system) with an airtermination system and down-conductor system positioned in such a way that the path of the lightning current can be in contact with the structure to be protected.

Note 3: Natural component of lightning protection system [6] 
Conductive component installed not specifically for lightning protection which can be used in addition to the LPS or in some cases could provide the function of one or more parts of the LPS.

Table 1. Electrical Characteristics on the Steel Used for Single Models and Models of high Rise Towers

\begin{tabular}{|l|c|}
\hline Relative Permeability $\mu_{\mathrm{r}}$ & 500 \\
\hline Saturation magnetic field $(\mathrm{T})$ & 3 \\
\hline Conductivity $\sigma(\mathrm{S} / \mathrm{m})$ & $7.0 \times 10^{6}$ \\
\hline
\end{tabular}

\subsubsection{Configurations of Models}

1. Single Models: Conductive cylindrical pipes

Single Models are conductive cylindrical pipes $600 \mathrm{~m}$ in length. Outer radiuses of the Single Models are $5 \times 10^{-3}, 5 \times 10^{-2}$ and $5 \times 10^{-1} \mathrm{~m}$. Bottoms of the Single Models are grounded with $0 \Omega$ and conducive current $\mathrm{I}_{\mathrm{ci}}$ can flow into tops of the Models without impedance. Longitudinal central axes of the Single Models are fixed along vertical $y$-axes of $x-y-z$ Cartesian coordinate system.

2. Models of high rise towers

Vertically standing up 15 conductive cylindrical pipes (down-conductors) are evenly located with equal interval in a circle around on the flat ground to introduce Models of high rise towers. The radius of the circle which contacts to the 15 conductive cylindrical pipes from outside is $20 \mathrm{~m}$. Each conductive cylindrical pipe is $600 \mathrm{~m}$ in length and $5 \times 10^{-1} \mathrm{~m}$ in radius. Edges of those conductive cylindrical pipes are electrically shorted each other at centers on tops and bottoms of the Models. The selfinductance and resistance on the conductors which connect the edges of the 15 conductive cylindrical pipes are neglected. The centers on the bottoms of the Models are grounded and current can run into the centers on the tops of the Models without impedance. The grounding resistance is given as 1,2 and $5 \Omega$ in consideration of general situations of high rise towers. The surface on the flat ground around the Models of high rise towers is assumed as perfect conductor with potential $0 \mathrm{~V}$. There isn't any conductive connection between the Models and the surface of the flat ground.

3. Group Models: Cylindrical conductors groups surrounded by metallic cylindrical outer coaxial pipes

Vertically standing up 15 cylindrical conductors are evenly located with equal interval in a circle around (cylindrical conductors groups). The radius of the circle which contacts to the 15 cylindrical conductors from outside is $20 \mathrm{~m}$. Each cylindrical conductor is $20 \mathrm{~m}$ in length and $5 \times 10^{-1} \mathrm{~m}$ in radius. Edges of the cylindrical conductors are electrically shorted each other at centers on tops and bottoms of the cylindrical conductors groups. The provisional potential along Models of high rise towers on each height $\varphi$ is given to the cylindrical conductors groups. Centers of cylindrical conductors groups are fixed at origin of $x-$ $y-z$ Cartesian coordinate system.

The metallic cylindrical outer coaxial pipes with $0 \Omega$ in grounding resistance are evenly located around the cylindrical conductors groups. Vertical length of the metallic cylindrical outer coaxial pipes is enough long for both directions compared to vertical width of the cylindrical conductors groups. Inner radius of the metallic cylindrical outer coaxial pipes is selected in order to simulate the capacitive coupling between the Models of high rise towers on each height and the flat ground (refer to 3.10).

\subsection{Waveforms on Conductive Current of Lightning Return Strokes}

The conductive current on the typical lightning short return strokes $I_{c}(t) 10 / 350 \mu s \quad$ [6] and $1 / 200 \mu s$ [13] expressed with equation (16) is applied to Single Models. And, the conductive current $I_{c}(t)$ is applied to tops on Models of high rise towers assuming that the lightning flashes are characterized as upward flashes. In the cases of the Models of high rise towers, entire conductive current of lightning return strokes $I_{c}(t)$ is evenly allocated to each conductive cylindrical pipe of the Models as conductive current $I_{\mathrm{ci}}(\mathrm{t})$. The conductive current waveforms of the typical lightning short return strokes $10 / 350 \mu$ s and $1 / 200 \mu \mathrm{s}$ are shown in Fig. (1a, b).

$I_{c}(t)=\frac{I_{p}}{\eta} \frac{\left(\frac{t}{\tau_{1}}\right)^{10}}{1+\left(\frac{t}{\tau_{1}}\right)^{10}} \exp \left(-\frac{t}{\tau_{2}}\right)$

, where

$I_{c}(t)$ : Time dependence on conductive current of lightning short return strokes (A)

$\mathrm{I}_{\mathrm{p}}$ : Peaks on conductive current waveforms of lightning short return strokes $(\mathrm{A})$

$\mathrm{t}$ : Time (s)

$\eta: 0.93, \tau_{1}: 19 \times 10^{-6}(\mathrm{~s}), \tau_{2}: 485 \times 10^{-6}(\mathrm{~s})$ for $10 / 350 \mu \mathrm{s}$

$\eta: 0.986, \tau_{1}: 1.82 \times 10^{-6}(\mathrm{~s}), \tau_{2}: 285 \times 10^{-6}(\mathrm{~s})$ for $1 / 200 \mu \mathrm{s}$

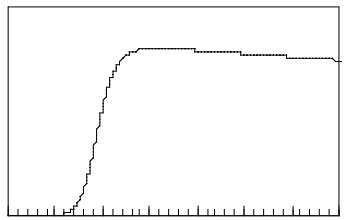

010203040506070

Time (_s)

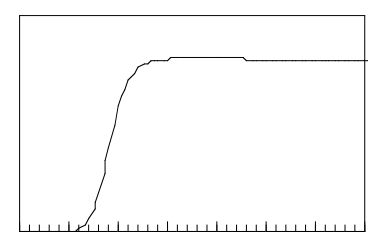

$\begin{array}{llllllll}0 & 1 & 2 & 3 & 4 & 5 & 6 & 7\end{array}$

Time (_s) (a) $10 / 350 \mu \mathrm{s}$ [6] (b) $1 / 200 \mu \mathrm{s}$ [13]

Fig. (1). Conductive current waveforms of typical lightning short return strokes.

\subsection{Distribution of Conductive Current Density within Single Models in Consideration of Skin Effect}

The vertical conductive current density located the most outside within Single Models is selected as the $\vec{j}_{\mathrm{c}}(t, a)$ which 
gives satisfaction of equation (17) referred to the equation (12). The conductive current $\mathrm{I}_{\mathrm{ci}}(\mathrm{t})$ indicated right side of the equation (17) is given by the equation (16) (refer to Note 4).

Note 4: $I_{c i}(t)$ is entire conductive current of lightning return strokes $I_{c}(t)$ on the Single Models. On conductive cylindrical pipes in Models of high rise towers, $I_{c i}(t)$ is $1 / 15$ on the entire conductive current of the lightning return strokes $I_{c}(t)$.

$$
\iint_{S} \vec{j}_{c}(t, a) e^{-\frac{a-x}{\delta(t)}} \cdot d \vec{S}_{x}=I_{c i}(t)
$$

$\mathrm{dS}_{\mathrm{x}}$ : Ringed vector element in horizontal cross sections of vertically standing up Single Models on the areal integration dimensioned by x-axes

The horizontal distribution on the vertical conductive current density within the conductive cylindrical pipes $\vec{j}_{c}(t$, $\mathrm{x}$ ) is expressed with the equation (12) using the $\mathrm{j}_{\mathrm{c}}(\mathrm{t}, \mathrm{a})$ and the equations (11)

\subsection{Outline on self-inductance of Single Models}

The magnetic energy is stored around flow of conductive current. Area around the current flow has self-inductance. When unit current is conducting along the flow, the selfinductance is the number on the magmatic flux which intersects the flow. The self-inductance of Single Models consists of external self-inductance $\mathrm{L}_{\mathrm{ex}}$ and internal selfinductance $\mathrm{L}_{\mathrm{in}}$. The external self-inductance $\mathrm{L}_{\mathrm{ex}}$ and the internal self-inductance $\mathrm{L}_{\mathrm{in}}$ correspond with the magnetic energy stored outside and inside of conductors, respectively. The external self-inductance per meter $\mathrm{L}_{\mathrm{ex} / 1}$ can be expressed as shown in equation (18) as well known.

$L_{e x / l}=\frac{\mu_{o}}{2 \pi}\left(\ln \frac{2 l}{a}-1\right)$

, where

$\mathrm{L}_{\mathrm{ex} / \mathrm{l}}$ : External self-inductance per meter of Single Models $(\mathrm{H} / \mathrm{m})$

\section{1: Length of Single Models (m)}

The precise internal self-inductance per meter $\mathrm{L}_{\mathrm{in} / 1}$ can be estimated with the numerical calculation taking into account the distribution of conductive current density $\vec{j}_{c}(t, x)$ and magnetic field $B_{\text {in }}(t, x)$ within the Single Models owing to skin effect (refer to 3.5 ).

\subsection{Internal Self-Inductance Per Meter of Single Models in Consideration of Skin Effect}

The magnetic energy stored within activated Single Models is expressed by equation (19) taking into account skin effect (refer to Note 4).

$\frac{1}{2} L_{i n}(t) I_{c i}(t)^{2}=\frac{1}{2} \int I_{c i x}(t, x) d \Phi$

$=\frac{1}{2} \int_{y} \int_{x} I_{c i x}(t, x) B_{i n}(t, x) d x d y$

, where

$\mathrm{L}_{\text {in }}(\mathrm{t})$ : Internal self-inductance of Single Models in consideration of skin effect $(\mathrm{H})$
$\mathrm{I}_{\mathrm{ci}}(\mathrm{t})$ : Conductive current of lightning return strokes along Single Models (A)

$\mathrm{I}_{\text {cix }}(\mathrm{t}, \mathrm{x})$ : Conductive current along Single Models within the horizontal circles with radius $x$ centered on $y$-axes (A)

$\mathrm{B}_{\text {in }}(\mathrm{t}, \mathrm{x})$ : Horizontal distribution of magnetic field within Single Models (T)

$\mathrm{d} \Phi$ : Element on magnetic flux integration within Single Models

$\mathrm{dx}$ : Element on line integration along $\mathrm{x}$-axes within Single Models

dy: Element on line integration along y-axes within Single Models

Based on the equation (19), the internal self-inductance per meter $\mathrm{L}_{\mathrm{in} / 1}(\mathrm{t})$ of the Single Models can be calculated as shown in equation (20).

$L_{i n / l}(t)=\frac{\int_{x} I_{c i x}(t, x) B_{i n}(t, x) d x}{I_{c i}(t)^{2}}$

The conductive current $\mathrm{I}_{\text {cix }}(\mathrm{t}, \mathrm{x})$ and the magnetic field $\mathrm{B}_{\text {in }}(\mathrm{t}, \mathrm{x})$ indicated in equation (20) are able to be given by the equations (21), (22) (refer to 7.2 Appendix 2) and the saturation magnetic field. If the magnetic field $B_{\text {in }}(t, x)$ calculated with the equation (22) is larger than the saturation magnetic field $3 \mathrm{~T}$, the value of the saturation magnetic field must be applied instead of the calculation results. The distribution of conductive current density $\overrightarrow{\mathrm{j}}_{\mathrm{c}}(\mathrm{t}, \mathrm{x})$ used on the equations (21) and (22) can be expressed with the equations (12) and the $\mathrm{j}_{\mathrm{c}}(\mathrm{t}, \mathrm{a})$ on the paragraph 3.3 taking into account skin effect.

$$
\begin{aligned}
& I_{c i x}(t, x)=\iint_{S} \vec{j}_{c}(t, x) \cdot d \vec{S}_{x} \\
& B_{\text {in }}(t, x)=\frac{\mu_{r} \mu_{0}}{2 \pi x} \iint_{S} \vec{j}_{c}(t, x) \cdot d \vec{S}_{x}
\end{aligned}
$$

\subsection{Equivalent Resistance Per Meter of Single Models in Consideration of Skin Effect}

The energy loss along Single Models owing to conductive current $\mathrm{I}_{\mathrm{ci}}(\mathrm{t})$ can be expressed with the equivalent resistance $R_{s u}(t)$ taking into account decrease of conductive area due to skin effect as shown in equation (23) (refer to Note 4).

$$
I_{c i}(t)^{2} R_{s u}(t)=\int_{y} \iint_{S} \frac{j_{c}(t, x)^{2}}{\sigma} d S_{x} d y
$$

, where

$\mathrm{R}_{\mathrm{su}}(\mathrm{t})$ : Equivalent resistance of Single Models in consideration of skin effect $(\Omega)$

$\sigma:$ Conductivity of Single Models $(\mathrm{S} / \mathrm{m})$

The equivalent resistance per meter $R_{\text {su/l }}(t)$ is able to be expressed with the equation (24) arranged from the equation (23). The horizontal distribution of conductive current density $\mathrm{j}_{\mathrm{c}}(\mathrm{t}, \mathrm{x})$ on the equations (24) can be expressed with the equations (12) and the $\vec{j}_{\mathrm{c}}(\mathrm{t}, \mathrm{a})$ on the paragraph 3.3. 
$R_{\text {sull }}(t)=\frac{\iint_{S} j_{c}(t, x)^{2} d S_{x}}{\sigma I_{c i}(t)^{2}}$

3.7. Capacitance Per Meter of Group Models Between Cylindrical Conductors Groups and Metallic Cylindrical Outer Coaxial Pipes

The horizontal electric field $\overrightarrow{\mathrm{E}}$ along $\mathrm{x}$-axes between cylindrical conductors groups and grounded metallic cylindrical outer coaxial pipes is selected for evaluation on capacitance of Group Models. The capacitance is defined with equation (25).

$$
C=\frac{\iint \rho_{s u}(t) d S}{\varphi(t)}
$$

, where

$\varphi(\mathrm{t})$ : Potential on cylindrical conductors groups of Group Models (V)

$\rho_{\mathrm{su}}(\mathrm{t})$ : Equivalent surface charge density in neighborhood of $\mathrm{x}$-axes on outer side surfaces in cylindrical conductors groups of Group Models $\left(\mathrm{C} / \mathrm{m}^{2}\right)$

dS: Element of areal integration on outer side in cylindrical conductors groups of Group Models

Since the equipotential surfaces close to the outer side of the cylindrical conductors groups are approximately formed cylindrically around on neighborhood of $\mathrm{x}$-axes, the horizontal surface electric field on the outer side of the cylindrical conductors groups $\mathrm{E}(\mathrm{t}, \mathrm{x})$ is expressed with equation (26) based on the Maxwell's equation (2) using the equivalent surface charge density $\rho_{\text {su }}(t)$ (refer to 7.3 Appendix 3).

$E(t, x)=\frac{\iint \rho_{s u}(t) d S}{2 \pi x l \varepsilon_{0}}$

, where

$\mathrm{E}(\mathrm{t}, \mathrm{x})$ : Horizontal electric field along $\mathrm{x}$-axes between cylindrical conductors groups and grounded metallic cylindrical outer coaxial pipes on Group Models (V/m)

Because, the electric field $\mathrm{E}(\mathrm{t}, \mathrm{x})$ is horizontally radiated from the outer side of the cylindrical conductors groups until the inner side of the grounded metallic cylindrical outer coaxial pipes, the potential on the outer side of the cylindrical conductors groups $\varphi(t)$ can be expressed with equation (27).

$\varphi(t)=-\int_{a_{p}}^{a_{g}} E(t, x) d x=\frac{\iint \rho_{s u}(t) d S}{2 \pi \varepsilon_{0} l} \ln \frac{a_{p}}{a_{g}}$

, where

$\mathrm{a}_{\mathrm{g}}$ : Outer radius on cylindrical conductors groups of Group Models (m)

$a_{p}$ : Inner radius on metallic cylindrical outer coaxial pipes of Group Models (m)

The capacitance per meter $\mathrm{C}_{/ 1}$ between the cylindrical conductors groups and the grounded metallic cylindrical outer coaxial pipes is expressed by equation (28) stems from the equations (25) and (27) on the evaluation using the horizontal electric field along $\mathrm{x}$-axes $\mathrm{E}(\mathrm{t}, \mathrm{x})$.

$$
C_{/ l}=\frac{2 \pi \varepsilon_{0}}{\ln \frac{a_{p}}{a_{g}}}
$$

\subsection{Potential difference per meter along Single Models}

The potential difference per meter along Single Models $\varphi_{\text {Lex/l/ }}(t), \varphi_{\text {Lin/l }}(t)$ and $\varphi_{\text {Rsu/l }}(t)$ can be expressed as shown in equations (29), (30) and (31) using the external selfinductance per meter $\mathrm{L}_{\mathrm{ex} / \mathrm{l}}$, internal self-inductance per meter $\mathrm{L}_{\mathrm{in} / 1}(\mathrm{t})$ and equivalent resistance per meter $\mathrm{R}_{\mathrm{su} / 1}(\mathrm{t})$ indicated on the equations (18), (20) and (24), respectively (refer to Note 4).

$\varphi_{\text {Lex/l }}(t)=L_{e x / l} \frac{\partial I_{c i}(t)}{\partial t}$

$\varphi_{\text {Lin/l }}(t)=L_{i n / l}(t) \frac{\partial I_{c i}(t)}{\partial t}$

$\varphi_{\text {Rsu/l }}(t)=R_{\text {su/l }}(t) I_{c i}(t)$

, where

$\varphi_{\text {Lex/l }}(t)$ : Potential difference per meter along Single Models based on effect in external self-inductance (V)

$\varphi_{\text {Lin/l/ }}(\mathrm{t})$ : Potential difference per meter along Single Models based on effect in internal self-inductance (V)

$\varphi_{\mathrm{Rsu} / \mathrm{l}}(\mathrm{t})$ : Potential difference per meter along Single Models based on effect in equivalent resistance $(\mathrm{V})$

\subsection{Provisional Potential Along Models of High Rise Towers}

The provisional potential along Models of high rise towers $\varphi_{\text {Lex }}(t), \varphi_{\text {Lin }}(t)$ and $\varphi_{\text {Rsu }}(t)$ stems from the effects in the external self-inductance, internal self-inductance and equivalent resistance of conductive cylindrical pipes (downconductors) is calculated at evaluation height $500 \mathrm{~m}$ and 60 $m$ with equations (32)-(34) and the equations (29)-(31) on the assumption that the typical conductive current of lightning return strokes $I_{\text {ci }}(t)$ is applied along the conductive cylindrical pipes of the Models without deformation of the conductive current. The typical waveforms on the conductive current of the lightning return strokes $10 / 350 \mu \mathrm{s}$ and $1 / 200 \mu \mathrm{s}$ are selected in trial for the evaluation height $500 \mathrm{~m}$ and 60 $\mathrm{m}$, respectively. The effects in the propagation of conductive current $I_{c}(t)$ and potential $\varphi(t)$ along the Models are neglected on calculation of this paper (refer to 5.2 and 6.1).

$\varphi_{\text {Lex }}(t)=\int \varphi_{\text {Lex/l }}(t) d y$

$\varphi_{\text {Lin }}(t)=\int \varphi_{\text {Lin/l }}(t) d y$

$\varphi_{\text {Rsu }}(t)=\int \varphi_{\text {Rsull }}(t) d y$

, where

$\varphi_{\text {Lex }}(t)$ : Provisional potential along Models of high rise towers based on effect in external self-inductance of conductive cylindrical pipes (V) 
$\varphi_{\text {Lin }}(\mathrm{t})$ : Provisional potential along Models of high rise towers based on effect in internal self-inductance of conductive cylindrical pipes (V)

$\varphi_{\text {Rsu }}(\mathrm{t})$ : Provisional potential along Models of high rise towers based on effect in equivalent resistance of conductive cylindrical pipes $(\mathrm{V})$

The potential along the Models of high rise towers $\varphi_{\mathrm{Rg}}(\mathrm{t})$ biased by the effect on the conductive current $\mathrm{I}_{\mathrm{c}}(\mathrm{t})$ running into grounding resistance of the Models $R_{g}$ can be expressed as shown in equation (35). The biased potential $\varphi_{\mathrm{Rg}}(\mathrm{t})$ indicated on the equation (35) isn't provisional.

$\varphi_{R g}(t)=R_{g} I_{c}(t)$

, where

$\varphi_{\mathrm{Rg}}(\mathrm{t})$ : Potential along Models of high rise towers based on effect of grounding resistance $(\mathrm{V})$

3.10. Provisional Electric Field, Displacement Current Density and Displacement Current Along Models of High Rise Towers Evaluated by Group Models

The displacement current density $\vec{j}_{d}(t)$ and displacement current $I_{d}(t)$ between cylindrical conductors groups and metallic cylindrical outer coaxial pipes on Group Models are able to be expressed with equations (36) and (37) using the horizontal surface electric field $\vec{E}(t)$ in neighborhood of $x-$ axes on outer side of the cylindrical conductors groups.

$$
\begin{aligned}
\vec{j}_{d}(t) & =\varepsilon_{0} \frac{\partial \vec{E}(t)}{\partial t} \\
I_{d}(t) & =\iint \varepsilon_{0} \frac{\partial E(t)}{\partial t} d S
\end{aligned}
$$

The horizontal electric field $\vec{E}(t)$ and $E(t)$ on the equations (36) and (37) can be expressed with equation (38) using potential on the cylindrical conductors groups $\varphi(t)$. The equation (38) is derived from the equations (26) and (27).

$$
E(t)=E\left(t, a_{g}\right)=\frac{\varphi(t)}{a_{g} \ln \frac{a_{p}(y)}{a_{g}}}
$$

From there, when the provisional potential along Models of high rise towers $\varphi(t)$ is given to the potential $\varphi(t)$ on the equation (38), the tendencies on the provisional displacement current density $\overrightarrow{\mathrm{j}}_{d}(\mathrm{t})$, displacement current $\mathrm{I}_{d}(\mathrm{t})$ and electric field $\vec{E}(\mathrm{t})$ caused along the Models of high rise towers can be calculated with the equations (36), (37) and (38). The provisional potential $\varphi(t)$, electric field $E(t)$, displacement current density $\vec{j}_{d}(t)$ and displacement current $I_{d}(t)$ can be separately evaluated as "effects of external self-inductance $\varphi_{\text {Lex }}(\mathrm{t}), \mathrm{E}_{\text {Lex }}(\mathrm{t}), \overrightarrow{\mathrm{j}}_{\mathrm{dLex}}(\mathrm{t})$ and $\mathrm{I}_{\mathrm{dLex}}(\mathrm{t})$ ", "effects of internal self-inductance $\varphi_{\text {Lin }}(t), E_{L \text { in }}(t), j_{d \text { Lin }}(t)$ and $I_{d L i n}(t)$ ", "effects of equivalent resistance $\varphi_{\text {Rsu }}(t), E_{R s u}(t), \vec{j}_{d R s u}(t)$ and $I_{d R s u}(t)$ " and "effects of grounding resistance $\varphi_{R g}(t), E_{R g}(t), j_{d R g}(t)$ and $I_{d R g}(t)$ " stems from the equations (32)-(35). The inner radius of metallic cylindrical outer coaxial pipes $a_{p}(y)$ on the equation (38) which intimates level of the capacitive coupling between the Models of high rise towers on each height and the flat ground is estimated with the numerical electric field analysis taking into account configuration on the Model of high rise towers (refer to 7.4 Appendix 4). That is to say, the inner radius of the cylindrical coaxial pipes $a_{p}$ (y) is derived as the indicators on the capacitive coupling in the Group Models between the cylindrical conductors groups and the metallic cylindrical outer coaxial pipe which simulate the intimated capacitive coupling. The inner radius of cylindrical coaxial pipes $a_{p}(y)$ is shown in Fig. (2) corresponding with the evaluation height along the Models of high rise towers. Numerical calculation program is able to be simplified by the equation (38) with the radius $a_{p}(y)$.

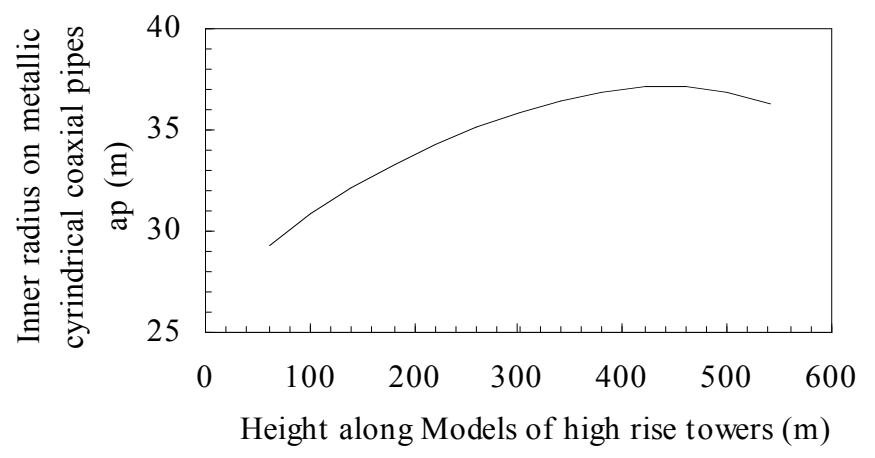

Fig. (2). Inner radius on metallic cylindrical outer coaxial pipes of Group Models characterized by evaluation height along Models of high rise towers.

\subsection{Conditions and Tools on Numerical Calculation}

Conditions and tools on numerical calculation are summarized in Table 2.

\section{CALCULATION RESULTS}

\subsection{Skin Effect within Single Models}

The horizontal distribution of the vertical conductive current density within Single Models $\overrightarrow{\mathrm{j}}_{\mathrm{c}}(t, x)$ is calculated with the equations (11), (12), (16) and (17) in consideration of skin effect. The calculated results are shown in Fig. (3) to express a typical case.

\section{2. "Self-Inductance and Resistance of Single Models" and "Capacitance of Group Models"}

4.2.1. "External Self-Inductance Per Meter and DCResistance Per Meter of Single Models" and "Capacitance Per Meter of Group Models"

The "external self-inductance and dc-resistance of Single Models" and "capacitance of Group Models between cylindrical conductors groups and metallic cylindrical outer coaxial pipes" are shown in Table 3 with indication of per meter. The external self-inductance per meter of the Single Models and the capacitance per meter of the Group Models are calculated with the equations (18) and (28), respectively.

\subsubsection{Internal Self-Inductance Per Meter of Single Models in Consideration of Skin Effect}

Internal self-inductance per meter of Single Models is calculated in consideration of skin effect with the equations (12) and (20)-(22) varying the radius of the Single Models and the magnitude on conductive current of lightning return strokes. Calculation results are shown in Figs. (4-6) to be 
Table 2. Conditions and Tools on Numerical Calculation

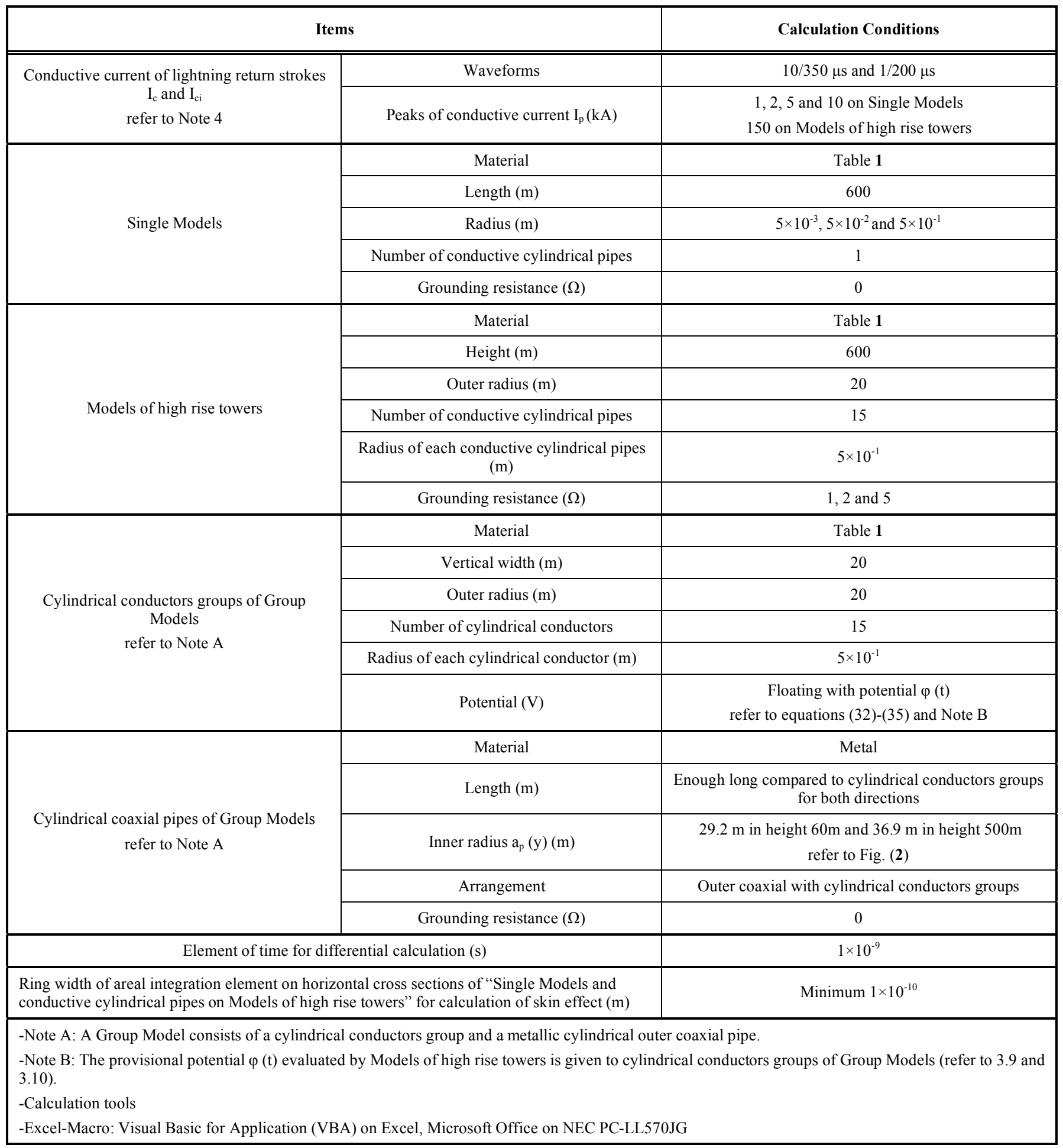

compared each other on the typical current waveforms of the lightning return strokes $10 / 350 \mu$ s and $1 / 200 \mu$ s.

The internal self-inductance of Single Models is larger or nearly the same in smaller radius on the same lightning return stroke waveform with the same current peak $I_{p}$ as shown in the Figs. (4-6). And, the internal self-inductance is larger in current waveforms with lower frequencies on the same current peak $\mathrm{I}_{\mathrm{p}}$ and the same Single Models as shown in the Figs. $(\mathbf{5}, \mathbf{6})$. Especially, the internal self-inductance is large on the tail in conductive current waveforms of typical lightning return strokes.

Because, on the current waveforms with lower frequencies and the Single Models with smaller radius, conductive current $\mathrm{I}_{\text {cix }}(t, x)$ more inwardly exists within the Single Models to cause stronger magnetic field $\vec{B}_{\text {in }}(t, x)$ in wider area within the Single Models as shown in the equation (20). Those influences are based on the skin effect depending on the radius of the Single Models and the 
angular frequencies of the conductive current waveforms $\omega$ (t) (refer to equations (11), (12), (21) and (22) and saturation magnetic field). Furthermore, the internal self-inductance is larger in smaller current peaks $I_{p}$ on the same lightning return stroke waveforms and the same Single Models in radius $5.0 \times 10^{-2}$ and $5.0 \times 10^{-3} \mathrm{~m}$ as shown in the Figs. $(\mathbf{4}, \mathbf{5})$. Because, more magnetic field $B_{\text {in }}(t, x)$ isn't beyond saturation magnetic field $3 \mathrm{~T}$ at the equation (20) in smaller conductive current on the condition. The internal selfinductance is constant independently of current peaks $I_{p}$ on the same lightning return stroke waveform and the same Single Models in radius $5.0 \times 10^{-1} \mathrm{~m}$. Because, magnetic field $\overrightarrow{\mathrm{B}}_{\text {in }}(\mathrm{t}, \mathrm{x})$ isn't beyond saturation magnetic field $3 \mathrm{~T}$ at the equation (20) in the current peaks $\mathrm{I}_{\mathrm{p}}$ ranging from $1 \mathrm{kA}$ to 10 $\mathrm{kA}$ on the condition.

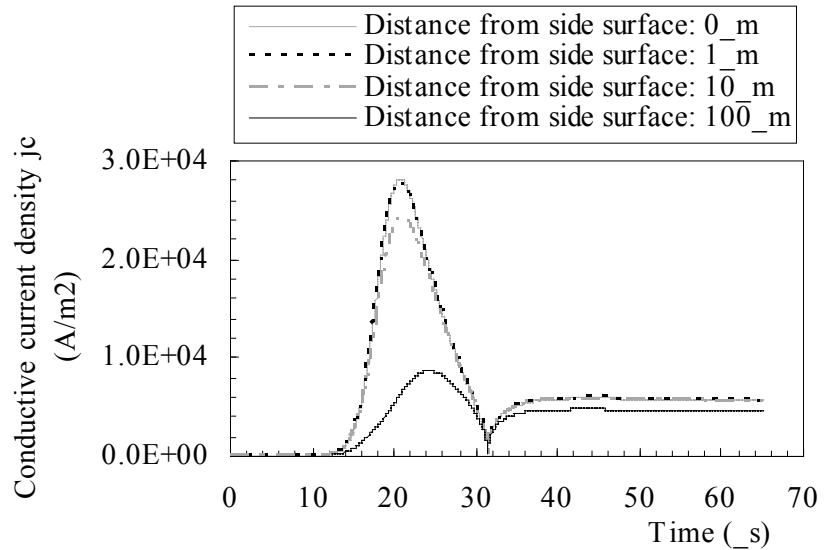

-Activated by conductive current of lightning return stroke $10 / 350 \mu \mathrm{s}, 10 \mathrm{kA}$ -Radius of Single Model $5 \times 10^{-1} \mathrm{~m}$

Fig. (3). Distribution on conductive current density within Single Models based on skin effect.

\subsubsection{Equivalent Resistance Per Meter of Single Models in Consideration of Skin Effect}

The equivalent resistance per meter of Single Models is calculated in consideration of skin effect with the equations (11), (12) and (24) varying radius of the Models. The calculation results are shown in Figs. $(\mathbf{7}, \mathbf{8})$ to be compared each other on the typical current waveforms of lightning return strokes $10 / 350 \mu$ s and $1 / 200 \mu$ s.

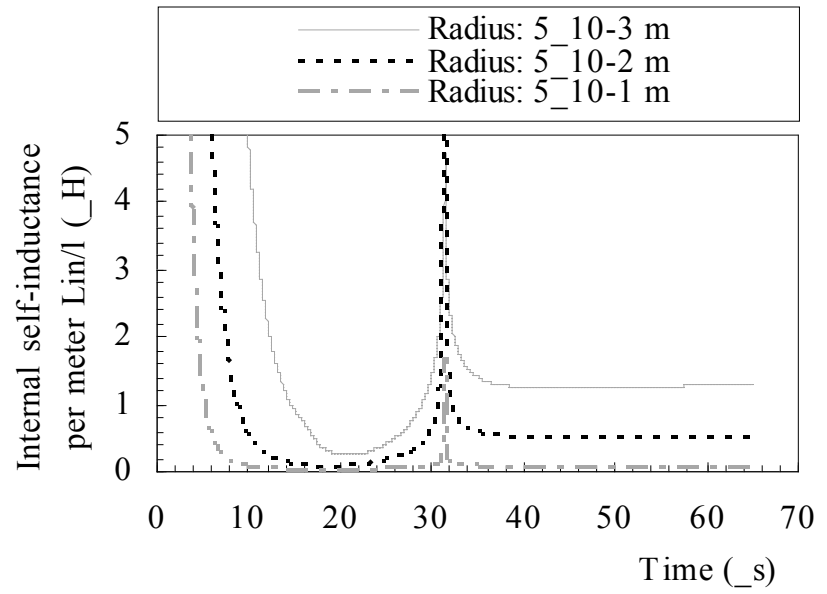

-Activated by conductive current of lightning return stroke $10 / 350 \mu \mathrm{s}, 1 \mathrm{kA}$

Fig. (4). Internal self-inductance per meter of Single Models in consideration of skin effect.

$\mathrm{n}$ the same lightning return stroke waveform with the same current peak $I_{p}$, the equivalent resistance of Single Models is larger in smaller radius as shown in the Figs. (7, 8). Because, more conductive current density $\vec{j}_{\mathrm{c}}(t, x)$ exists within the narrower conductive area beneath outer surfaces along the Single Models as shown in the equation (24) based

Table 3. "External Self-Inductance and dc-Resistance of Single Models" and "Capacitance of Group Models"

\begin{tabular}{|c|c|c|}
\hline Items & Radius (m) & - \\
\hline \multirow{3}{*}{ External self-inductance per meter of Single Models $(\mu \mathrm{H})$ refer to equation (18) Note A } & $5.0 \times 10^{-3}$ in outer radius & 2.31 \\
\hline & $5.0 \times 10^{-2}$ in outer radius & 1.84 \\
\hline & $5.0 \times 10^{-1}$ in outer radius & 1.38 \\
\hline \multirow{3}{*}{ Resistance per meter of Single Models on direct current $(\mathrm{m} \Omega)$} & $\begin{array}{l}5.0 \times 10^{-3} \text { in outer radius } \\
4.0 \times 10^{-3} \text { in inner radius }\end{array}$ & 5.06 \\
\hline & $\begin{array}{l}5.0 \times 10^{-2} \text { in outer radius } \\
3.0 \times 10^{-2} \text { in inner radius }\end{array}$ & $\underset{2}{2.84 \times 10^{-}}$ \\
\hline & $\begin{array}{l}5.0 \times 10^{-1} \text { in outer radius } \\
4.8 \times 10^{-1} \text { in inner radius }\end{array}$ & $\underset{3}{2.32 \times 10^{-}}$ \\
\hline \multirow{2}{*}{$\begin{array}{c}\text { Capacitance per meter of Group } \\
\text { Models between cylindrical conductors groups and metallic cylindrical outer coaxial } \\
\text { pipes }(\mathrm{pF}) \text { refer to equation }(28) \text { Note B }\end{array}$} & $36.9 \mathrm{~m}$ in inner radius of cylindrical coaxial pipes & 90.8 \\
\hline & $29.2 \mathrm{~m}$ in inner radius of cylindrical coaxial pipes & 146.4 \\
\hline \multicolumn{3}{|c|}{$\begin{array}{l}\text {-Note A: Length of Single Models is } 600 \mathrm{~m} \text { on calculation. } \\
\text {-Note B: } \\
\text {-Outer radius of cylindrical conductors groups is } 20 \mathrm{~m} \text {. } \\
\text {-The "inner radiuses of metallic cylindrical outer coaxial pipes } \mathrm{a}_{\mathrm{p}} \text { (y) } 36.9 \mathrm{~m} \text { and } 29.2 \mathrm{~m} \text { " correspond with capacitive coupling between "Models of high } \\
\text { rise towers on height y } 500 \mathrm{~m} \text { and } 60 \mathrm{~m} \text { " and "the flat ground around the Models", respectively (refer to 3.10). }\end{array}$} \\
\hline
\end{tabular}


on the skin effect depending on radius of the Single Models (refer to equation (12)) on the condition, too. Furthermore, the equivalent resistance of the Single Models is larger in current waveforms with higher frequencies on the same Single Models as shown in the Figs. $(7,8)$. Because, more conductive current density $\overrightarrow{\mathrm{j}}_{\mathrm{c}}(t, x)$ exteriorly exists within the Single Models to make narrow conductive area in the equation (24) based on the skin effect depending on angular frequencies of the current waveforms $\omega$ (t) (refer to equations (11) and (12)) on the condition. The equivalent resistance of the Single Models is constant independently of current peaks $I_{p}$ on the same lightning return stroke waveforms and the same Single Models.

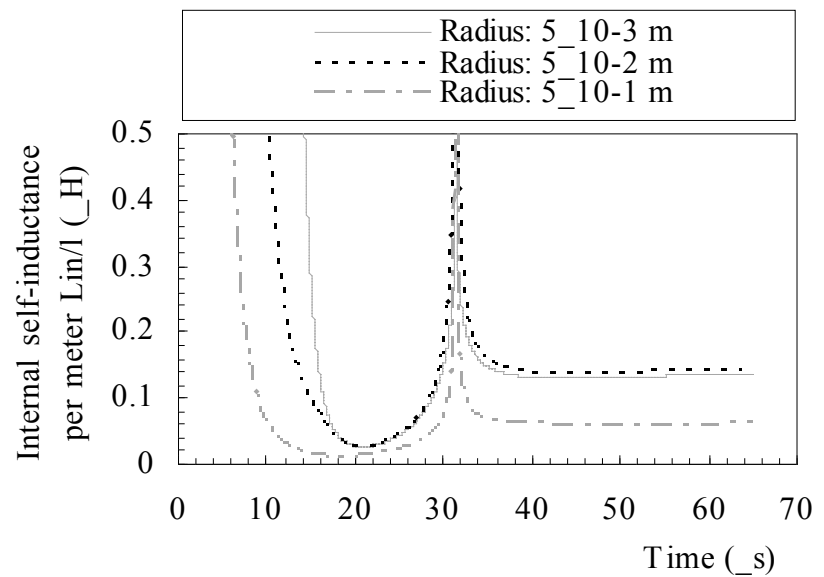

-Activated by conductive current of lightning return stroke $10 / 350 \mu \mathrm{s}, 10 \mathrm{kA}$

Fig. (5). Internal self-inductance per meter of Single Models in consideration of skin effect.

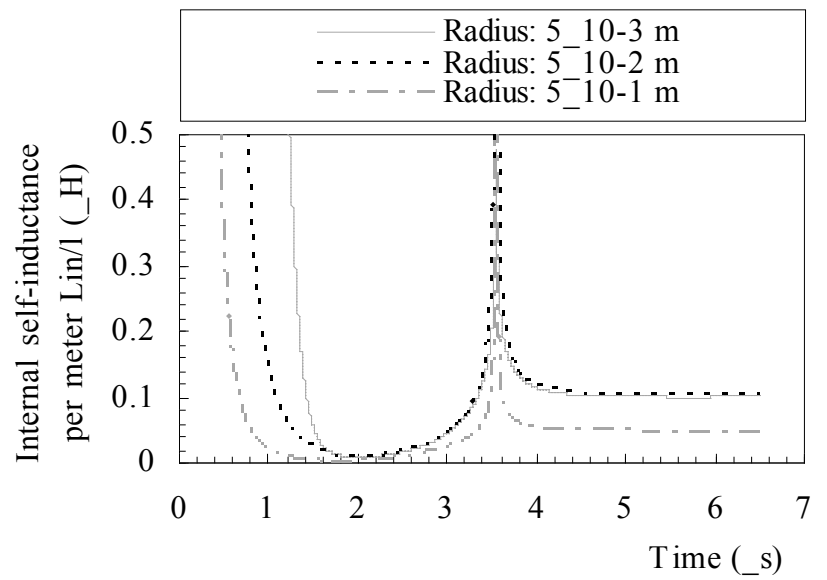

-Activated by conductive current of lightning return stroke $1 / 200 \mu \mathrm{s}, 10 \mathrm{kA}$

Fig. (6). Internal self-inductance per meter of Single Models in consideration of skin effect.

\subsection{Potential Difference Per Meter Along Single Models}

The potential difference per meter along activated Single Models $\varphi_{/ 1}(\mathrm{t})$ based on the effects in the external selfinductance $\varphi_{\text {Lex/1 }}(\mathrm{t})$, internal self-inductance $\varphi_{\text {Lin/1 }}(\mathrm{t})$ and equivalent resistance $\varphi_{\text {Rsu/l }}(\mathrm{t})$ is calculated with the equations (18), (20), (24) and (29)-(31). The calculation results are shown in Table 4, Figs. $(\mathbf{9}, \mathbf{1 0})$ to be compared each other on the typical conductive current waveforms of lightning return strokes $10 / 350 \mu$ s and $1 / 200 \mu$ s varying radius of the Single Models and magnitude of the conductive current. The potential difference per meter along the Single Models owing to the effects of the internal self-inductance $\varphi_{\text {Lin/1 }}(t)$ and the equivalent resistance $\varphi_{\mathrm{Rsu} / \mathrm{l}}(\mathrm{t})$ is indicated in the percentage to the potential difference per meter along the Single Models owing to the effect of the external selfinductance $\varphi_{\text {Lex } / 1}(t)$ on the Table 4 .

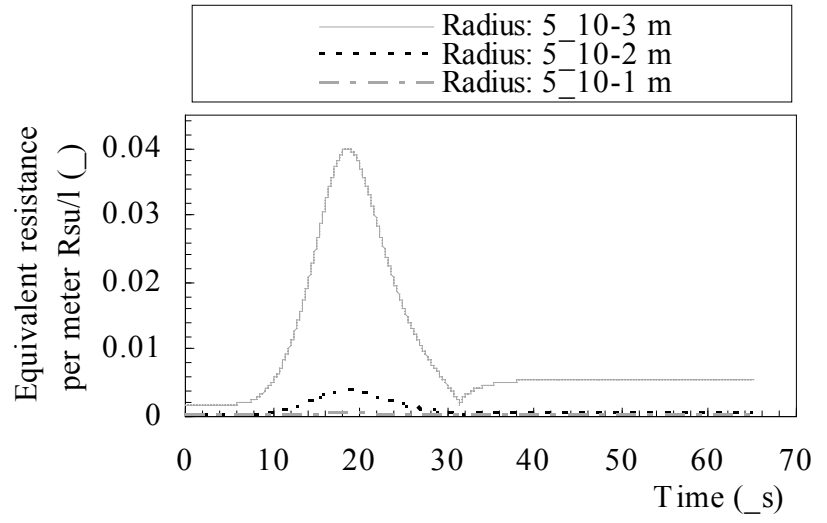

-Activated by conductive current of lightning return stroke $10 / 350 \mu \mathrm{s}, 10 \mathrm{kA}$

Fig. (7). Equivalent resistance per meter of Single Models in consideration of skin effect.

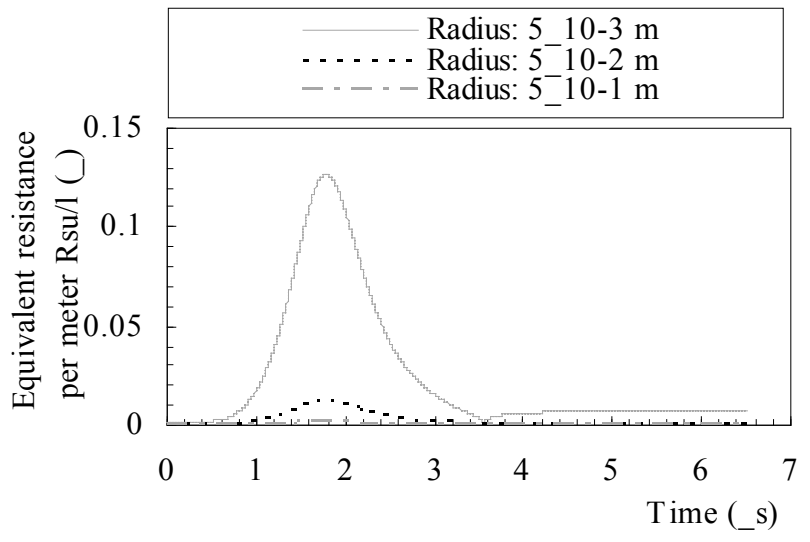

-Activated by conductive current of lightning return stroke $1 / 200 \mu \mathrm{s}, 10 \mathrm{kA}$

Fig. (8). Equivalent resistance per meter of Single Models in consideration of skin effect.

On the lower rising frequencies in the conductive current waveforms of lightning return strokes and the smaller radius in Single Models, the effect in the internal self-inductance $\varphi_{\text {Lin/1 }}(t)$ taking into account skin effect is larger in potential rise along the Single Models as shown in the Table 4. And, on the smaller peaks in the conductive current waveforms of the lightning return strokes, the effect of the internal selfinductance $\varphi_{\mathrm{Lin} / 1}(\mathrm{t})$ is larger in the potential rise along the Single Models with radius $5 \times 10^{-3}$ and $5 \times 10^{-2} \mathrm{~m}$ as shown in the Table 4. The effect of internal self-inductance $\varphi_{\text {Lin/1 }}(t)$ is independently of peaks of the conductive current waveforms on the potential rise along the Single Models with radius $5 \times 10^{-1} \mathrm{~m}$ as shown in the Table 4. Meanwhile, on the lower rising frequencies in the conductive current waveforms of 
Table 4. Potential Difference Along Single Models Due to Effects of Internal Self-Inductance and Equivalent Resistance on Indication in Percentage to Potential Difference Along Single Models Due to Effect of External Self-Inductance

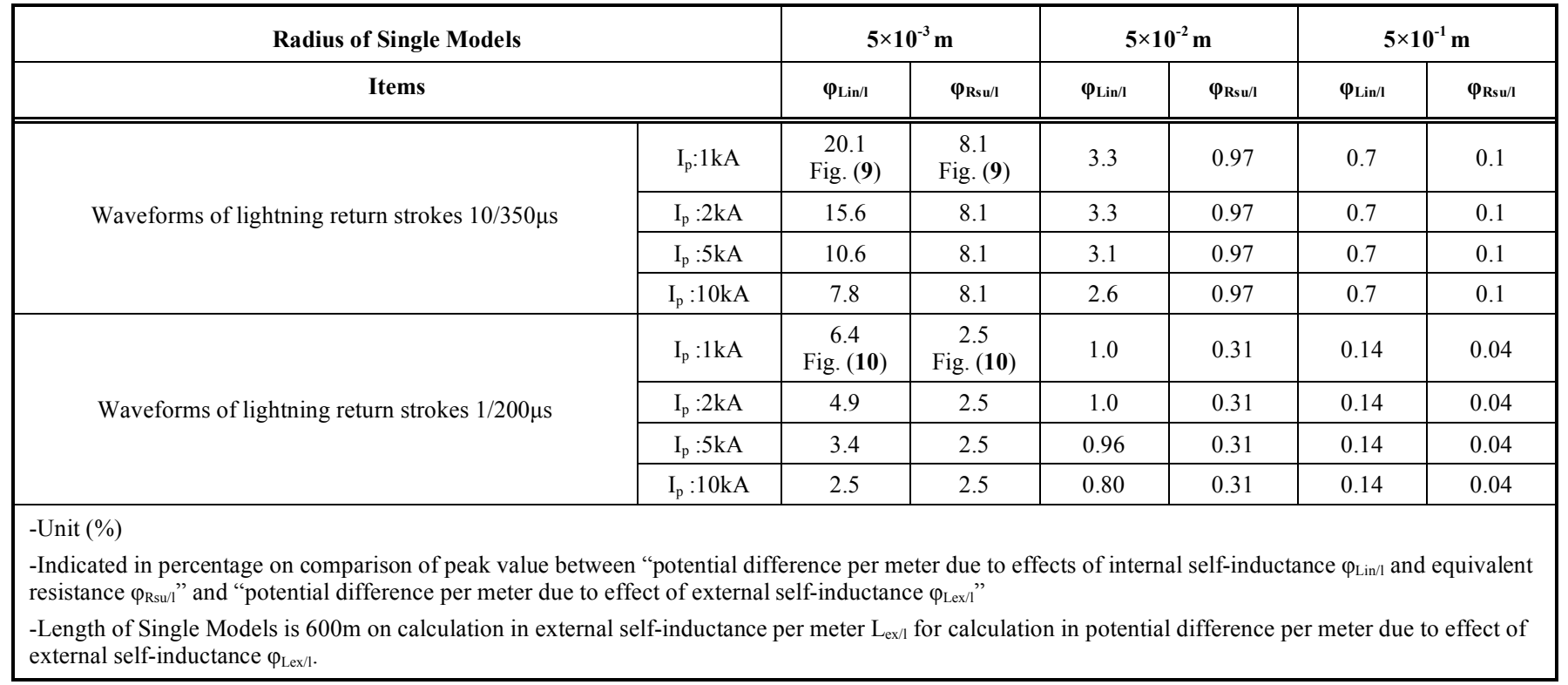

the lightning return strokes and the smaller radius in the Single Models, the effect in the equivalent resistance $\varphi_{\text {Rsu/l }}(t)$ taking into account skin effect is larger in the potential rise along the Single Models as shown in the Table 4. The effect in the equivalent resistance on the potential rise along the Single Models $\varphi_{\text {Rsu/l }}(t)$ is independently of the peaks on the conductive current waveforms of the lightning return strokes as shown in the Table 4.

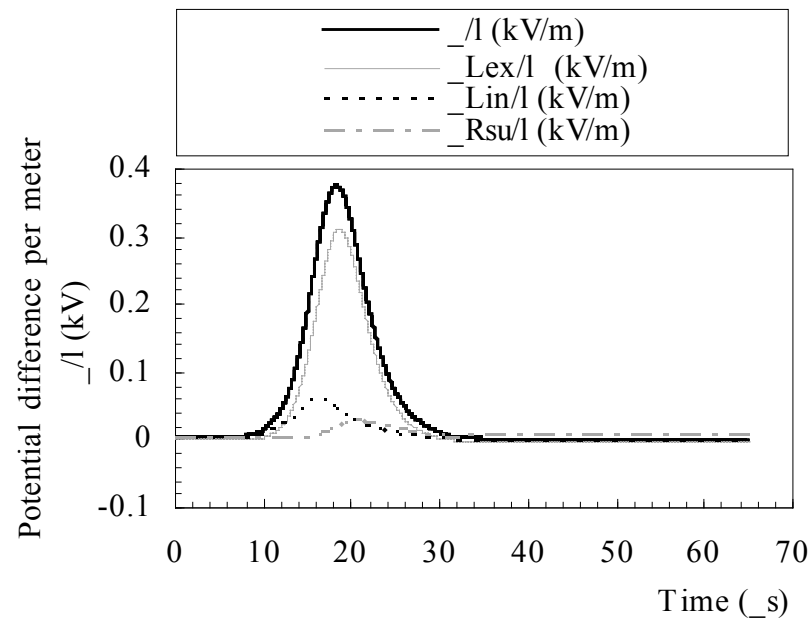

-Activated by conductive current of lightning return stroke $10 / 350 \mu \mathrm{s}, 1 \mathrm{kA}$

-Radius of Single Model $5 \times 10^{-3} \mathrm{~m}$

Fig. (9). Potential difference per meter along Single Models based on effects in external self-inductance, internal self-inductance and equivalent resistance.

Practically speaking in lightning protection, the effects in internal self-inductance $\varphi_{\mathrm{Lin} / 1}(\mathrm{t})$ and equivalent resistance $\varphi_{\text {Rsu/l }}(t)$ can be neglected compared to the effect in external self-inductance $\varphi_{\text {Lex } / 1}(t)$ on the potential rise along the thick Single Models installed for the main down-conductors of high rise towers for example $5 \times 10^{-1} \mathrm{~m}$ in radius. Because, the percentage between "potential rise owing to effects in internal self-inductance and equivalent resistance" and "potential rise owing to effect in external self-inductance" is small as less than $1 \%$ on comparison in peak value as shown in the Table 4.

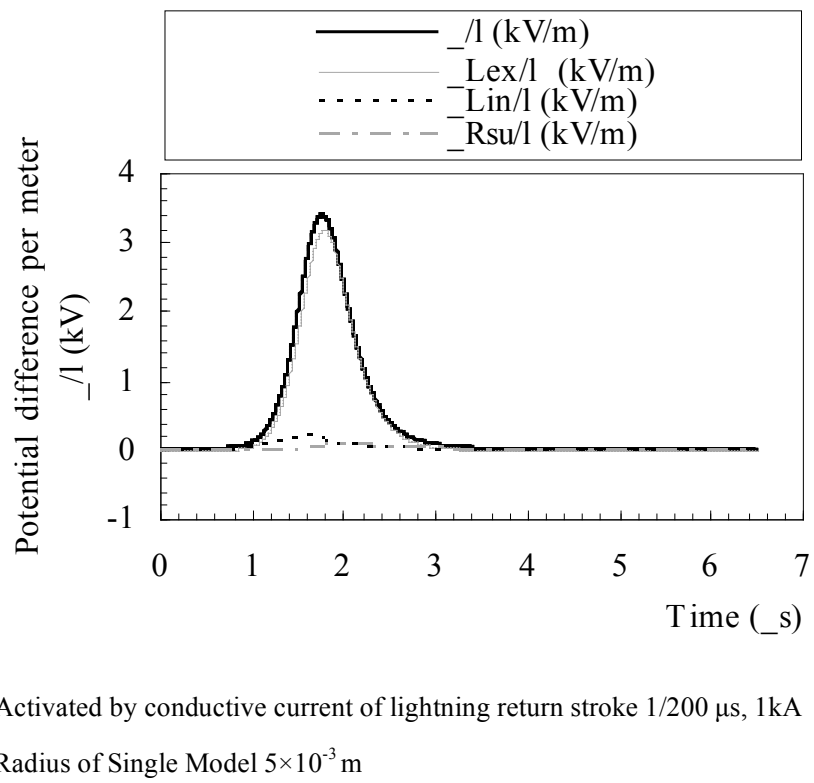

Fig. (10). Potential difference per meter along Single Models based on effects in external self-inductance, internal self-inductance and equivalent resistance.

In the cases of the lightning return strokes characterized by the low rising frequency $10 / 350 \mu$ s and small conductive current peak $1 \mathrm{kA}$ on Single Models with small radius $5 \times 10^{-3}$ $\mathrm{m}$, the effect of internal self-inductance $\varphi_{\mathrm{Lin} / 1}(\mathrm{t})$ is $20.1 \%$ for the effect of external self-inductance $\varphi_{\text {Lex } / 1}$ (t) on the comparison in peak value of rising potential along the Single Models as shown in the Fig. (9) and the Table 4. On the same condition, the effect of the equivalent resistance $\varphi_{\mathrm{Rsu} / 1}$ (t) taking into account skin effect is $8.1 \%$ for the effect of 
the external self-inductance $\varphi_{\text {Lex/l }}(t)$ on comparison in peak value of the rising potential as shown in the Fig. (9) and the Table 4. The total potential rise $\varphi_{/ 1}(\mathrm{t})$ owing to the $\varphi_{\text {Lex } / 1}(\mathrm{t})$, $\varphi_{\text {Rsu/l }}(\mathrm{t})$ and $\varphi_{\text {Lin/1 }}(\mathrm{t})$ is indicated on the Fig. (9), too. And, in the cases of the lightning return strokes characterized by the high rising frequency $1 / 200 \mu \mathrm{s}$ and small conductive current peak $1 \mathrm{kA}$ on the Single Models with small radius $5 \times 10^{-3} \mathrm{~m}$, the potential rises based on the effects in the external selfinductance $\varphi_{\text {Lex/l }}(\mathrm{t})$, the internal self-inductance $\varphi_{\text {Lin/l }}(\mathrm{t})$ and the equivalent resistance $\varphi_{\text {Rsu/l }}(\mathrm{t})$ are shown in Fig. (10) as well as the total potential rise $\varphi_{/ 1}(\mathrm{t})$.

\subsection{Tendencies on Provisional Potential Along Models of High Rise Towers}

The tendencies in the provisional potential in Models of high rise towers $\varphi(\mathrm{t})$ at height $500 \mathrm{~m}$ are calculated with the equations (32)-(35) as shown in Fig. (11) on condition in grounding resistance of the Models $2 \Omega$. The provisional potential $\varphi(t)$ is separately indicated as the effects in the external self-inductance of conductive cylindrical pipes $\varphi_{\text {Lex }}$ (t) and the grounding resistance of the Models $\varphi_{R g}(t)$ on the Fig. (11). The effects in the internal self-inductance $\varphi_{\text {Lin }}(t)$ and equivalent resistance $\varphi_{\text {Rsu }}(t)$ of the conductive cylindrical pipes are enough small to be neglected on the total potential $\varphi(\mathrm{t})$ (refer to 4.3$)$.

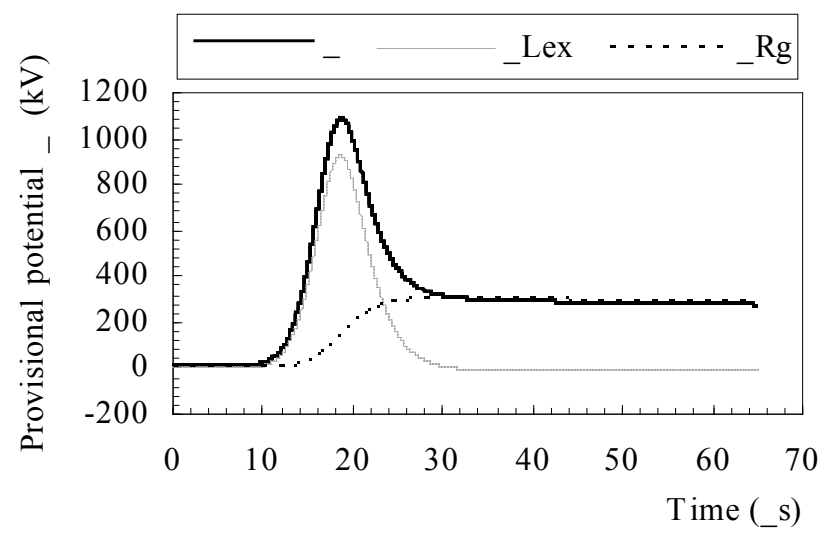

-Struck by conductive current of lightning return stroke 10/350 $\mu \mathrm{s}, 150 \mathrm{kA}$

-Radius of down-conductors (conductive cylindrical pipes) $5 \times 10^{-1} \mathrm{~m}$

-Grounding resistance of earth termination system $2 \Omega$

Fig. (11). Provisional potential along Models of high rise towers on height $500 \mathrm{~m}$.

4.5. Tendencies on the Provisional Electric Field Along Models of High Rise Towers Evaluated by Group Models

The tendencies on the provisional surface electric field in Models of high rise towers $\overrightarrow{\mathrm{E}}(\mathrm{t})$ at height $500 \mathrm{~m}$ are calculated with Group Models using the equation (38), the equations (29)-(35) and the results in the numerical electric field analysis along the Models of high rise towers, or the inner radius of metallic cylindrical outer coaxial pipes $a_{p}(y)$ (refer to Fig. 2 and Table 3 ) as shown in Fig. (12). The provisional surface electric field $\vec{E}(\mathrm{t})$ is expressed varying the grounding resistance in the earth termination system in the Models of high rise towers as 1,2 and $5 \Omega$ on the Fig. (12).

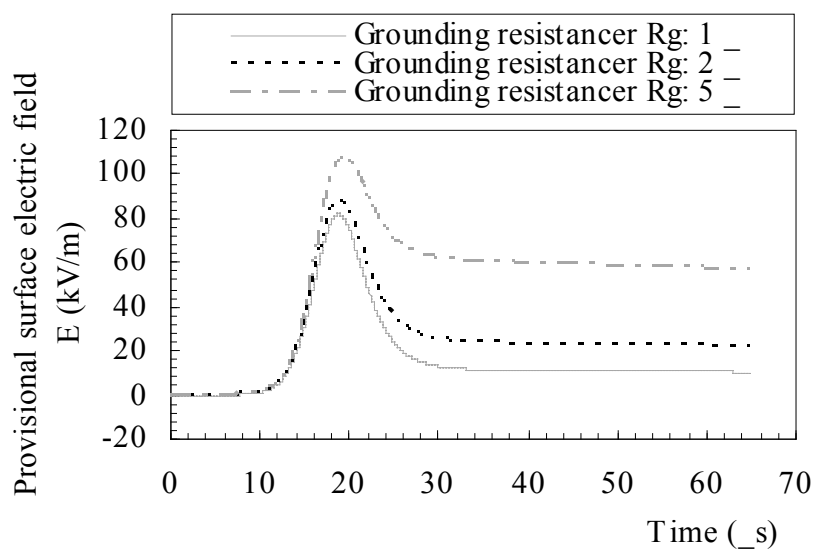

-Struck by conductive current of lightning return stroke 10/350 $\mu \mathrm{s}, 150 \mathrm{kA}$

-Radius of down-conductors (conductive cylindrical pipes) $5 \times 10^{-1} \mathrm{~m}$

Fig. (12). Provisional surface electric field along Models of high rise towers on height $500 \mathrm{~m}$.

4.6. Tendencies on diverging in the provisional displacement current density along Models of high rise towers evaluated by Group Models

The tendencies in the diverging in the provisional displacement current density along Models of high rise towers $\overrightarrow{\mathrm{j}}_{\mathrm{d}}(\mathrm{t})$ at height $500 \mathrm{~m}$ and $60 \mathrm{~m}$ are evaluated with Group Models using the equations (36), (38) and equations (29)-(35) as shown in Figs. $(13,14)$ on condition in grounding resistance of the Models $2 \Omega$, respectively. On the Figs. $(13,14)$, the provisional displacement current density $\vec{j}$ dLex $(t)$ and $\vec{j}_{d R g}(t)$ as the effects in the external selfinductance of conductive cylindrical pipes $\mathrm{L}_{\mathrm{ex}}$ and the grounding resistance of the Models $R_{g}$ are separately expressed. The effects in the internal self-inductance $\vec{j}_{\text {Lin }}(t)$ and equivalent resistance $\overrightarrow{\mathrm{j}}_{\text {Rsu }}(\mathrm{t})$ of the conductive cylindrical pipes are enough small to be neglected on appearance of total displacement current density $\mathrm{j}_{d}(t)$ (refer to 4.3$)$.

4.7. Tendencies on Diverging in the Provisional Displacement Current Per Meter Along Models of High Rise Towers Evaluated by Group Models

The tendencies on the diverging in the provisional displacement current per meter along Models of high rise towers $I_{d}(t)$ at height $500 \mathrm{~m}$ and $60 \mathrm{~m}$ are evaluated with Group Models using the equations (37), (38) and the equations (29)-(35) as shown in Figs. $(\mathbf{1 5}, \mathbf{1 6})$, respectively. The provisional displacement current per meter $I_{d}(t)$ is expressed varying the grounding resistance on the earth termination system in the Models of high rise towers as 1, 2 and $5 \Omega$ on the Figs. $(15,16)$.

\section{CONDUCTIVE CURRENT ALONG THE HIGH RISE TOWERS STRUCK BY LIGHTNING RETURN STROKES TAKING INTO ACCOUNT DIVERGING OF DISPLACEMENT CURRENT}

\subsection{Experimental Tendencies}

The tendencies on the conductive current waveforms of lightning return strokes along high rise towers $I_{c}$ which have 


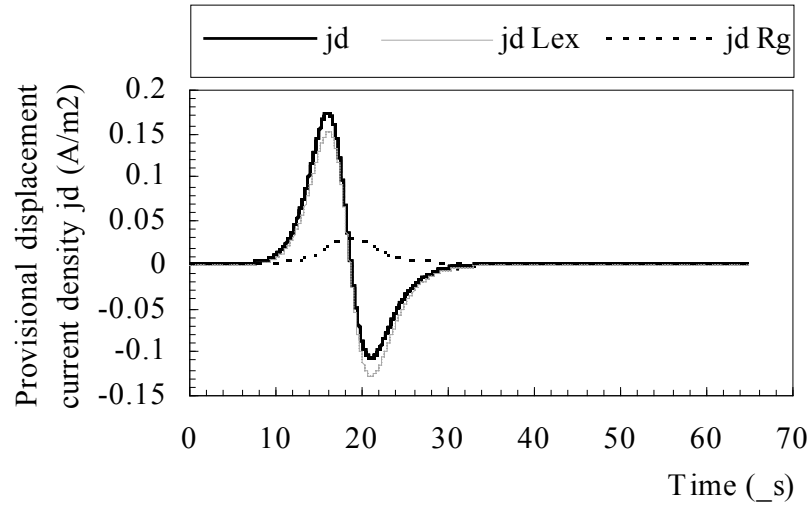

-Struck by conductive current of lightning return stroke $10 / 350 \mu \mathrm{s}, 150 \mathrm{kA}$

-Radius of down-conductors (conductive cylindrical pipes) $5 \times 10^{-1} \mathrm{~m}$

-Grounding resistance of earth termination system $2 \Omega$

Fig. (13). Diverging on provisional displacement current density along Models of high rise towers at height $500 \mathrm{~m}$.

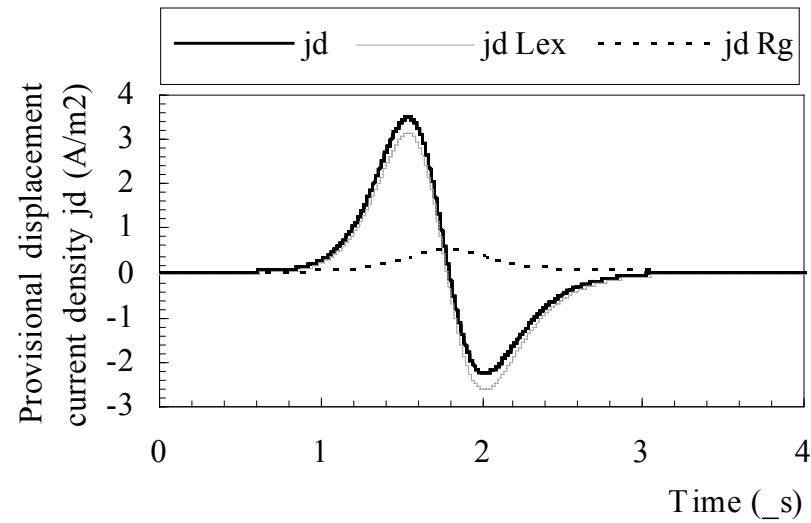

-Struck by conductive current of lightning return stroke 1/200 $\mu \mathrm{s}, 150 \mathrm{kA}$

-Radius of down-conductors (conductive cylindrical pipes) $5 \times 10^{-1} \mathrm{~m}$

-Grounding resistance of earth termination system $2 \Omega$

Fig. (14). Diverging on provisional displacement current density along Models of high rise towers at height $60 \mathrm{~m}$.

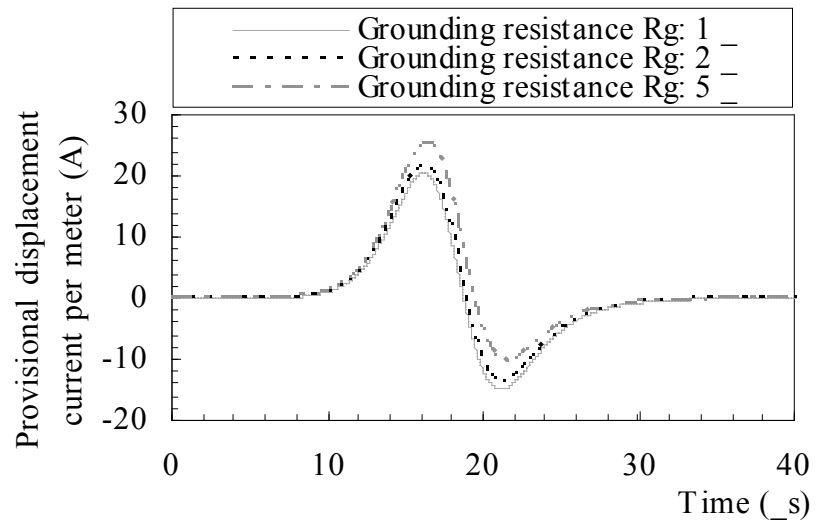

-Struck by conductive current of lightning return stroke 10/350 $\mu$ s, $150 \mathrm{kA}$

-Radius of down-conductors (conductive cylindrical pipes) $5 \times 10^{-1} \mathrm{~m}$

Fig. (15). Diverging on provisional displacement current per meter along Models of high rise towers at height $500 \mathrm{~m}$.

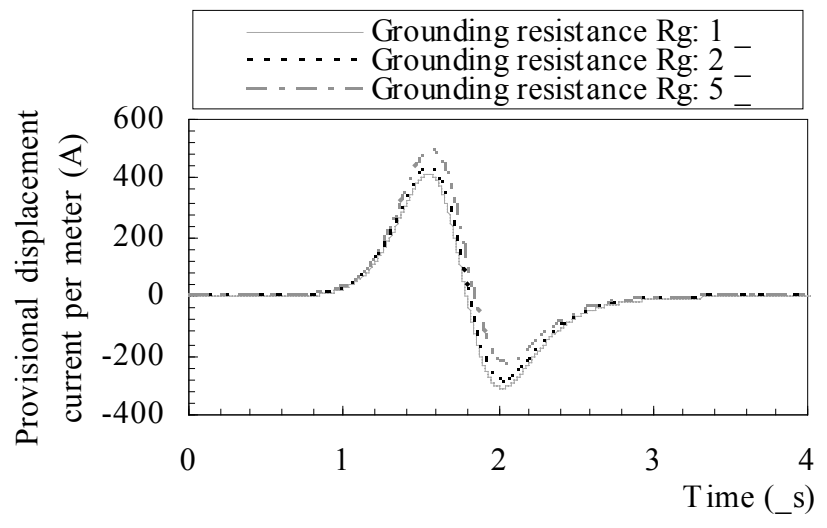

-Struck by conductive current of lightning return stroke $1 / 200 \mu \mathrm{s}, 150 \mathrm{kA}$

-Radius of down-conductors (conductive cylindrical pipes) $5 \times 10^{-1} \mathrm{~m}$

Fig. (16). Diverging on provisional displacement current per meter along Models of high rise towers at height $60 \mathrm{~m}$.

been already measured are shown in Figs. $(\mathbf{1 7}, \mathbf{1 8})[9,10]$. The peaks of the conductive current $I_{p}$ drastically decrease corresponding with rise of evaluation height along the towers as shown in the Fig. (17). The duration on wave fronts of the conductive current waveforms $\mathrm{d}_{\mathrm{f}}$ increases corresponding with the rise of the evaluation height along the towers as shown in the Fig. (18).

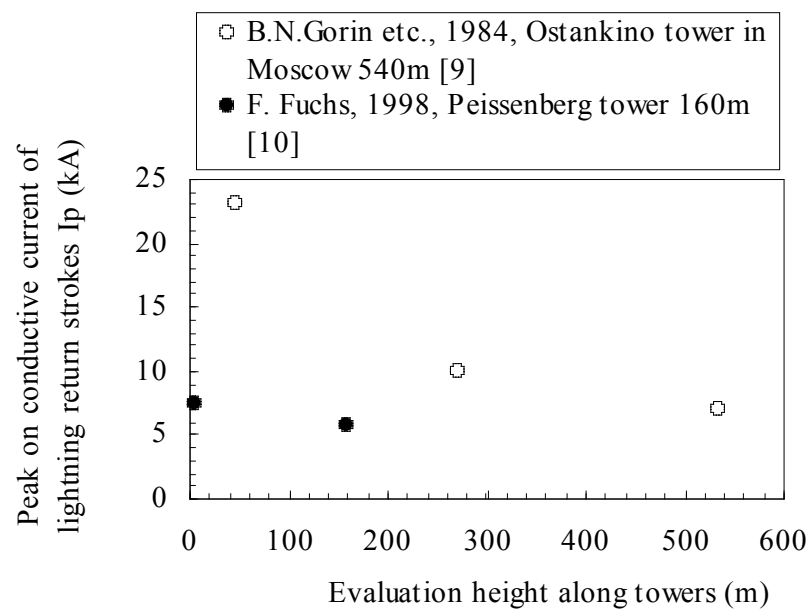

Fig. (17). Experimental tendencies on peaks in conductive current of lightning return strokes along high rise towers.

The rising frequencies of the conductive current waveforms $f_{r}$ decrease corresponding with the rise of the evaluation height along the towers as analogized by the Fig. (18).

\subsection{Explanation Based on Theoretical Analysis}

The conductive current of lightning short return strokes $I_{c}$ (t) is applied to tops on Models of high rise towers in order to explain the experimental results (refer to Figs. 17, 18) assuming that the lightning flashes are characterized as upward flashes. The conductive current of the lightning return strokes $I_{c}(t)$ propagates along the Models accompanied by the transfer between the conductive current $I_{c}(t)$ and the displacement current $I_{d}(t)$. The transfer is expressed by the equation (15) with the electric field $\vec{E}(\mathrm{t})$ (refer to the equation (38)) owing to the potential $\varphi(t)$ (refer 
to the equations (32)-(35)). The deformation on the conductive current waveforms along the Models $I_{c}(t)$ indicated in the Figs. $(\mathbf{1 7}, \mathbf{1 8})$ can be explained based on the transfer taking into account the propagation process with velocity of the light $\mathrm{c}$ in the conductive current $\mathrm{I}_{\mathrm{c}}(\mathrm{t})$ and the potential $\varphi(\mathrm{t})$ along the Models mentioned next paragraphs.

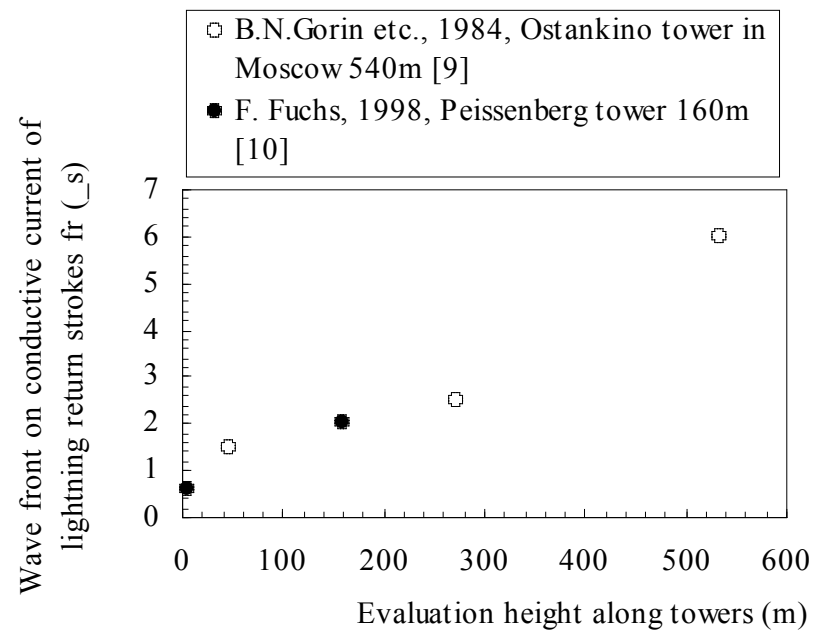

Fig. (18). Experimental tendencies on duration in wave front in conductive current of lightning return strokes along high rise towers.

\subsubsection{Propagation on Conductive Current and Potential Along Models of High Rise Towers}

It is necessary for the evaluation on the conductive current $I_{c}(t)$ and displacement current $I_{d}(t)$ along Models of high rise towers to eventually estimate potential along the Models $\varphi(\mathrm{t})$ as shown in the paragraphs 2.2, 3.9 and 3.10. The potential on an evaluation height along the Models $\varphi(t)$ must be calculated taking into account the "propagation of conductive current $I_{c}(t)$ from the tops to the positions at where potential is appeared (the positions on grounding resistance and on impedance in each part along downconductors)" and "propagation of potential $\varphi$ (t) from the positions at where potential is appeared to the positions at where potential is evaluated" along the Models. After all, the specification on the propagation time of the conductive current $I_{c}(t)$ and the potential $\varphi(t)$ must be take into account for the evaluation on the conductive current $I_{c}(t)$ and the displacement current $I_{d}(t)$ for the evaluation height along the Models as well as the specification on the potential $\varphi(t)$ in the positions at where the potential is appeared.

\subsubsection{Diverging in Displacement Current Along Models of High Rise Towers Based on Effect in Grounding Resistance}

The displacement current stems from the effect on grounding resistance in Models of high rise towers $I_{d R g}(t)$ (refer to Figs. (13-16) is transferred into the conductive current $I_{c}(t)$ based on the equation (15) taking into account the propagation along the Models in the conductive current $I_{c}$ (t) and the potential stems from the effect of the grounding resistance $\varphi_{R g}(t)$. The time delay owing to the distance between the position at where the potential is appeared (at the grounding resistance) and the positions at where potential is evaluated is one on the decision of the potential in an evaluation height along the Models $\varphi_{\text {Rg }}(t)$. Then, the much displacement current stems from effect of the grounding resistance $I_{d R g}(t)$ is directly added to the conductive current $I_{c}(t)$ on the evaluation height taking into account the one time delay. The added displacement current $I_{d}(t)$ exactly makes the peaks $I_{p}$ and rising frequencies $f_{r}$ of the conductive current $I_{c}(t)$ be larger on lower parts of the towers.

\subsubsection{Diverging in Displacement Current Along Models of High Rise Towers Based on Effects in Self-Inductance and Equivalent Resistance of Down-Conductors}

The displacement current stems from the effect on impedance (external self-inductance, internal self-inductance and equivalent resistance) in down-conductors (conductive cylindrical pipes) in Models of high rise towers $I_{d L e x}(t), I_{d L i n}$ (t) and $I_{d R s u}(t)$ (refer to Figs. 13-16) is transferred into the conductive current $I_{c}(t)$ based on the equation (15) taking into account the propagation along the Models on the conductive current $I_{c}(t)$ and the potential stems from the effect of the impedance $\varphi_{\text {Lex }}(t), \varphi_{\text {Lin }}(t)$ and $\varphi_{\text {Rsu }}(t)$. The conductive current along the Models $I_{c}(t)$ is affected by the multi time delay varying by the position on the each part along the Models at where the potential is originally appeared (the multi time delay on effect in impedance of each part along down-conductors). The potential of evaluation points along the Models $\varphi_{\text {Lex }}(t), \varphi_{\text {Lin }}(t)$ and $\varphi_{\text {Rsu }}$ (t) is the integration on the effects in the impedance in the each part along the down-conductors of the Models for height lower than the evaluation points. The potential integrated along the Models $\varphi_{\text {Lex }}(t), \varphi_{\text {Lin }}(t)$ and $\varphi_{\text {Rsu }}(t)$ is affected by the multi time delay varying by the position on the each part along the Models at where the potential is originally appeared (the multi time delay on effect in impedance of each part along down-conductors). Here, the multi time delay in the potential of the evaluation points $\varphi_{\text {Lex }}$ $(\mathrm{t}), \varphi_{\text {Lin }}(\mathrm{t})$ and $\varphi_{\text {Rsu }}(\mathrm{t})$ depends on the distance between the positions at where potential is appeared and the positions at where potential is evaluated. Then, the displacement current on an evaluation point $I_{d L e x}(t), I_{d L i n}(t)$ and $I_{d R s u}(t)$ stems from the integrated potential is numerically transferred into the conductive current $I_{c}(t)$ taking into account the multi time delay of the conductive current $I_{c}(t)$ and the potential $\varphi_{\text {Lex }}(\mathrm{t}), \varphi_{\text {Lin }}(\mathrm{t})$ and $\varphi_{\text {Rsu }}(\mathrm{t})$ (refer to 6.1).

The $I_{d \text { Lin }}(t)$ and $I_{d R s u}(t)$ based on $\varphi_{\text {Lin }}(t)$ and $\varphi_{\text {Rsu }}(t)$ can be neglected on the thick conductive cylindrical pipes used for main down-conductors of high rise towers as shown in the paragraph 4.3 .

\section{FUTURE TASKS}

\subsection{Numerical Calculation on Conductive Current Along the Models of High Rise Towers Struck by Lightning Return Strokes}

The deformation on the conductive current waveforms in lightning return strokes along Models of high rise towers $I_{c}$ (t) is going to be numerically calculated using the transfer theorem between conductive current $I_{c}(t)$ and displacement current $I_{d}(t)$. The calculation will be tried in consideration of "propagation time on current $I_{c}(t)$ and potential $\varphi(t)$ along Models of high rise towers", "effects in grounding resistance and impedance along down-conductors on calculation of potential along the Models $\varphi$ (t) (refer to 5.2)" and "capacitive coupling between the Models on each height and 
the flat ground around the Models". The effects on "potential along channels of lightning return storks (refer to 7.4.1)" and "potential on the flat ground around the Models owing to conductive current running into the grounding resistance $I_{c}$ (t) (refer to 7.4.2)" ought to be considered on the numerical calculation, too.

\subsection{Numerical Calculation on Conductive Current Along the Models of Large Size Buildings Struck by Lightning Return Strokes}

The deformation on the conductive current waveforms of lightning return strokes $I_{c}(t)$ must be evaluated along the large size buildings not so high which have large width or depth as well as high rise towers. The reasons of the trial are explained as follows.

Surface area on side of the large size buildings is enough large to cause strong capacitive coupling to the ground (refer to 2.2 and 3.10).

The potential stems from grounding resistance of earth termination system $\varphi_{\mathrm{Rg}}(\mathrm{t})$ along the large size buildings is exactly effectual to the diverging of displacement current along the buildings $\mathrm{I}_{\mathrm{dRg}}(\mathrm{t})$ as well as the potential stems from the grounding resistance along high rise towers $\varphi_{\mathrm{Rg}}(\mathrm{t})$ (refer to 3.9, 3.10 and 5.2). And, the grounding resistance on earth termination system in the large size buildings isn't small as that in the high rise towers (refer to 3.1.2 (2)). The many grounding resistance of the large size buildings is larger than 100 $\Omega$.

- $\quad$ Analytical trials are inevitable because the experiments corresponding with every down-conductor of the large size buildings are complicated.

\subsection{Establishment on the lightning parameters} characterized along high rise towers and large size buildings

The direction for the establishment on the lightning parameters characterized along sides of the large size buildings including high rise towers is going to be proposed taking into account the deformation on the conductive current waveforms of lightning return strokes along the sides of the large size buildings.

\section{CONCLUSIONS}

The "internal self-inductance and equivalent resistance on conductive cylindrical pipes with high relative permeability" and "potential difference per meter along activated conductive cylindrical pipes $\varphi_{/ 1}$ stems from effects in the internal self-inductance and the equivalent resistance" are evaluated in consideration of skin effect. Furthermore, the tendencies on the deformation in the conductive current of lightning return strokes along high rise towers $I_{c}$ are broadly explained stems from the analytical discussion taking into account the diverging of displacement current along the towers $I_{d}$. The typical conductive current waveforms of the lightning short return strokes $10 / 350 \mu$ s and $1 / 200 \mu$ s are used for evaluation. Main results of this paper are concluded as followers.

Theorem of skin effect is explained based on "Maxwell's equations related to Faraday's law, Ampere's law and Gaussian law" and "electric characteristic within conductors". Transfer theorem between conductive current $I_{c}$ and displacement current $I_{d}$ is explicated based on the Maxwell's equation related to Ampere's law. The transfer depends on the aspects in the formation in the time varying electric field $\vec{E}$ on surfaces of high voltage matter.

Single Models (conductive cylindrical pipes) are proposed for the evaluation on "the external selfinductance and the internal self-inductance and equivalent resistance taking into account skin effect on conductive cylindrical pipes" and "potential difference per meter along conductive cylindrical pipes $\varphi_{/ 1}$ based on effects in the external selfinductance, the internal self-inductance and the equivalent resistance". And, the Models of high rise towers with height $600 \mathrm{~m}$ struck by lightning return strokes are proposed to estimate provisional potential along the Models $\varphi$. Furthermore, the Group Models which can calculate the tendencies on the provisional electric field $\vec{E}$, displacement current density $\vec{j}_{d}$ and displacement current $I_{d}$ along the Models of high rise towers are proposed. A Group Model consists of a cylindrical conductors group and a metallic cylindrical outer coaxial pipe.

(3) The calculation methods on internal self-inductance of Single Models are explained in consideration of skin effect. And, the calculation results of the internal self-inductance are shown on the Single Models made from steel with high relative permeability as follows (refer to Figs. 4-6). The internal self-inductance of the Single Models is larger or nearly the same in smaller radius on the same lightning return stroke waveforms with the same current peak $I_{p}$. And, the internal selfinductance is larger in current waveforms with lower frequencies on the same current peak $\mathrm{I}_{\mathrm{p}}$ and the same Single Models. Especially, the internal selfinductance is large on the tail in conductive current waveforms of typical lightning return strokes. Furthermore, the internal self-inductance is larger in smaller current peaks $I_{p}$ on the same lightning return stroke waveforms and the same Single Models in radius $5.0 \times 10^{-2}$ and $5.0 \times 10^{-3} \mathrm{~m}$. The internal selfinductance is constant independently of current peaks $I_{p}$ on the same lightning return stroke waveforms and the same Single Models in radius $5.0 \times 10^{-1} \mathrm{~m}$. Reason on characteristics of the calculated results is explained with the theorem of skin effect and the mathematical expression of the internal selfinductance.

The calculation methods on equivalent resistance of Single Models are explained in consideration of skin effect. And, the calculation results of the equivalent resistance are shown on the Single Models made from steel with high relative permeability as follows (refer to Figs. 7, 8). On the same lightning return stroke waveform with the same current peak $\mathrm{I}_{\mathrm{p}}$, the equivalent resistance in the Single Models is larger on smaller radius. Furthermore, the equivalent resistance of the Single Models is larger in conductive current waveforms with higher frequencies on the same Single Models. The 
equivalent resistance of the Single Models is constant independently of current peaks $\mathrm{I}_{\mathrm{p}}$ on the same lightning return stroke waveforms and the same Single Models. Reason on characteristics of the calculated results is explained with the theorem of skin effect and the mathematical expression of the equivalent resistance.

The potential difference per meter along activated Single Models $\varphi_{\|}$stems from the effects in the external self-

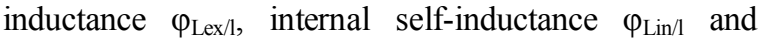
equivalent resistance $\varphi_{\text {Rsul }}$ is compared each other (refer to Table 4, Figs. 9, 10). On the lower rising frequencies in conductive current waveforms of lightning return strokes and the smaller radius in the Single Models, the effect in the internal self-inductance $\varphi_{\mathrm{Lin} / \mathrm{I}}$ taking into account skin effect is larger in potential rise along the Single Models. And, on the smaller peaks in the conductive current waveforms of the lightning return strokes, the effect of the internal self-inductance $\varphi_{\mathrm{Lin} / 1}$ is larger in the potential rise along the Single Models with radius $5 \times 10^{-3}$ and $5 \times 10^{-2} \mathrm{~m}$. The effect of the internal self-inductance $\varphi_{\mathrm{Lin} / \mathrm{I}}$ is independently of peaks of the conductive current waveforms on the potential rise along the Single Models with radius $5 \times 10^{-1} \mathrm{~m}$. Meanwhile, on the lower rising frequencies in the conductive current waveforms of the lightning return strokes and the smaller radius in the Single Models, the effect in the equivalent resistance $\varphi_{\text {Rsul }}$ taking into account skin effect is larger in the potential rise along the Single Models. The effect in the equivalent resistance on the potential rise along the Single Models $\varphi_{\text {Rsul }}$ is independently of the peaks on the conductive current waveforms of the lightning return strokes. Practically speaking, the effects in the internal self-inductance $\varphi_{\mathrm{Lin} / \mathrm{I}}$ and the equivalent resistance $\varphi_{\text {Rsul }}$ can be neglected compared to the effect in the external self-inductance $\varphi_{\mathrm{Lex} / 1}$ on the potential rise along the thick Single Models installed for the main down-conductors of high rise towers for example $5 \times 10^{-1}$ $\mathrm{m}$ in radius (refer to Table 4). In the cases of the lightning return strokes characterized by the low rising frequency $10 / 350 \mu$ s and small conductive current peak $1 \mathrm{kA}$ on the Single Models with small radius $5 \times 10^{-3} \mathrm{~m}$, the effects of the internal self-inductance $\varphi_{\mathrm{Lin} / 1}$ and the equivalent resistance $\varphi_{\text {Rsu/ }}$ taking into account skin effect are $20.1 \%$ and $8.1 \%$ for the effect of the external selfinductance $\varphi_{\text {Lex/l }}$ on comparison in peak value of rising potential, respectively (refer to Fig. 9 and Table 4).

The potential $\varphi$ and electric field $\overrightarrow{\mathrm{E}}$ along the Models of high rise towers struck by lightning return strokes are provisionally evaluated (refer to Figs. 11, 12). And, the diverging on the displacement current density $j_{d}$ along the Models of high rise towers is provisionally evaluated as the effects of external selfinductance $\overrightarrow{\mathrm{j}}_{\mathrm{dLex}}$ and grounding resistance $\overrightarrow{\mathrm{j}}_{\mathrm{dRg}}$, separately (refer to Figs. 13, 14). Furthermore, the diverging on the provisional displacement current per meter along the Models $I_{d}$ is evaluated varying the grounding resistance on earth termination system of the Models as 1,2 and $5 \Omega$ (refer to Figs. 15, 16). The calculation results on the displacement current density $\vec{j}_{d}$ and the displacement current per meter $I_{d}$ are provisionally shown on evaluation height $60 \mathrm{~m}$ and 500 $\mathrm{m}$. The effects on the internal self-inductance $\vec{j}_{d L i n}, I_{d L i n}$ and equivalent resistance $\overrightarrow{\mathrm{j}}_{\mathrm{dRsu}}$, $\mathrm{I}_{\mathrm{dRsu}}$ can be neglected on the appearance in the total displacement current density $\vec{j}_{d}$ and total displacement current per meter $I_{d}$.

The experimental tendencies on the conductive current of lightning return strokes along high rise towers $I_{c}$ which have been already measured are introduced (refer to Figs. 17, 18). The current peaks $I_{p}$ and rising frequencies $f_{r}$ on the conductive current of lightning return strokes $I_{c}$ drastically decrease corresponding with rise of evaluation height along the towers. Causes of the experimental results are broadly explained stems from the tendencies on the provisional calculation results in the diverging of the displacement current $I_{d}$ and displacement current density $\vec{j}_{d}$ along the Models of high rise towers.

\section{ACKNOWLEDGEMENT}

None declared.

\section{CONFLICT OF INTEREST}

None declared.

\section{ABOUT THE AUTHOR}

Hiroshi Kurita was born in 1960 in Japan and graduated from University of Waseda (Electrical Engineering) in 1984. He received the Doctorate degree on electrical engineering from University of Waseda in 1998.

\section{APPENDICES}

\section{Appendix 1 Deriving Process of Equation (9)}

Apply time differential to the Maxwell's equation (6). Furthermore, adopt the relation between conductive current density $\vec{j}_{c}$ and electric field $\vec{E}$ indicated in the equation (8) to get equation (A.1).

$\operatorname{rot} \frac{\partial \vec{B}}{\partial t}=\mu_{r} \mu_{0} \sigma \frac{\partial \vec{E}}{\partial t}$

Eliminate magnetic field $\overrightarrow{\mathrm{B}}$ from the equation (A.1) with the Maxwell's equation (1).

$-\operatorname{rotrot} \vec{E}=\mu_{r} \mu_{0} \sigma \frac{\partial \vec{E}}{\partial t}$

Apply the vector analysis formula (A.3) indicated below and the characteristics in electric field $\mathrm{E}$ within conductors expressed with the equitation (7) to the equitation (A.2) to be derived the equation (9).

$\operatorname{rotrot} \vec{E}=\operatorname{graddiv} \vec{E}-\nabla^{2} \vec{E}$

\section{Appendix 2 Deriving Process of Equation (22)}

Apply aerial integration to both sides of the Maxwell's equation (6) as shown in equation (A.4). The time dynamism and spatial extent in the magnetic field $\mathrm{B}_{\text {in }}(\mathrm{t}, \mathrm{x})$ and conductive current density $\vec{j}_{\mathrm{c}}(t, x)$ within conductive cylindrical pipes are taken into account on the equation (A.4).

$$
\iint_{S} \operatorname{rot} \vec{B}_{i n}(t, x) \cdot d \vec{S}_{x}=\mu_{r} \mu_{0} \iint_{S} \vec{j}_{c}(t, x) \cdot d \vec{S}_{x}
$$


And, adopt Stokes' formula on vector analysis to left side of the equation (A.4) to get equation (A.5).

$\oint \vec{B}_{i n}(t, x) \cdot d \vec{l}_{x}=\mu_{r} \mu_{0} \iint_{S} \vec{j}_{c}(t, x) \cdot d \vec{S}_{x}$

Then, the horizontal magnetic field within conductive cylindrical pipes $B_{\text {in }}(t, x)$ can be expressed with equation (22) based on the equation (A.5) and the formula to calculate circumferences $2 \pi x$.

\section{Appendix 3 Deriving Process of Equation (26)}

Apply volume integration to both sides of the Maxwell's equation (2) as shown in equation (A.6). The "time dynamism and spatial extent of electric field $\vec{E}(\mathrm{t}, \mathrm{x})$ " and "time dynamism of equivalent volume charge density $\rho_{\mathrm{vo}}(\mathrm{t})$ " are taken into account on the equation (A.6).

$$
\oiiint \operatorname{div} \vec{E}(t, x) d v=\frac{1}{\varepsilon_{0}} \iiint \rho_{v o}(t) d v
$$

And, adopt Gaussian formula on vector analysis to left side of the equation (A.6) to get equation (A.7).

$$
\oiint \vec{E}(t, x) \cdot d \vec{S}=\frac{1}{\varepsilon_{0}} \iiint \rho_{v o}(t) d v
$$

The equation (A.7) can be transformed into equation (A.8) because the equivalent charge owing to potential $\varphi(t)$ is concentrated on the outer surfaces in cylindrical conductors groups of Group Models.

$\oiint \vec{E}(t, x) \cdot d \vec{S}=\frac{1}{\varepsilon_{0}} \iint \rho_{s u}(t) d S$

The horizontal electric field along $\mathrm{x}$-axes $\overrightarrow{\mathrm{E}}(\mathrm{t}, \mathrm{x})$ can be expressed with equation (26) using the equation (A.8) and the formula to calculate area on side surfaces of cylindrical figures $2 \pi \times 1$.

Appendix 4 Condition on Numerical Analysis in Electric Field Along Model of High Rise Towers

\section{Neglect on Effect of Potential Along Channels of Lightning Return Storks}

The potential along channels of lightning return strokes is effectual to the formation on the surface electric field $\vec{E}(t)$ especially along upper parts of struck high rise towers. On the Models of high rise towers indicated this paper, the effect in existence in the channels of the lightning return strokes is neglected in the calculation of the electric field $\vec{E}(t)$, or the specification in the inner radius in cylindrical coaxial pipes of Group Models $\mathrm{a}_{\mathrm{p}}(\mathrm{y})$ (refer to 3.10).

Surface on the Flat Ground Around Models of High Rise Towers Assumed as Perfect Conductor with Potential OV
The surface electric field especially along lower parts on Models of high rise towers $\vec{E}(t)$ is affected by the potential on the flat ground around the Models owing to conductive current running into grounding resistance $\mathrm{I}_{\mathrm{c}}(\mathrm{t})$. On the Models of high rise towers indicated this paper, however, the surface on the flat ground around the Models is assumed as perfect conductor with potential $0 \mathrm{~V}$. And, there isn't the any conductive connection between the Models and the surface of the flat ground.

\section{Assumption of without Surroundings Except the Flat Ground}

The surroundings on Models of high rise towers (the flat ground, structures, mountains and hills etc.) which can be effectual to formation of surface electric field along the Models $\overrightarrow{\mathrm{E}}(\mathrm{t})$ don't exist except the flat ground.

\section{Neglect on Capacitive Coupling Among Parts Along Models of High Rise Towers}

The capacitive coupling among one part and the other parts along Models of high rise towers is neglected. Because, the potential deference along the Models among the one part and the other parts close to each other is extremely low. And, capacitance coupling along the Models among the one part and the other parts far from each other is little enough.

\section{REFERENCES}

[1] Rachidi F. The quandary of direct measurement and indirect estimation of lightning current parameters. Proceedings of the 27th International conference on lightning protection. Avignon: France 2004.

[2] Baba Y, Ishii M. Numerical electromagnetic field analysis of lightning current in tall structures: IEEE Trans Power Deliv 2001; 16(2): 324-8.

[3] Kurita H. Protection of persons from electric field caused by lightning. Proceedings of the $29^{\text {th }}$ International conference on lightning protection. Uppsala, Sweden 2008; pp. 8-16.

[4] Kurita H. Protection of persons from magnetic field caused by lightning, Proceedings of the $29^{\text {th }}$ International conference on lightning protection. Uppsala, Sweden 2008; pp. 8-17.

[5] Kurita H. Electric field and magnetic field caused by lightning return strokes. Proceedings of the 29th International conference on lightning protection. Uppsala, Sweden, Jun 2008; pp. 12-8.

[6] Protection against lightning Part 1. General principles. Jan 2006; BS EN 62305-1: 2011.

[7] Protection against lightning Part 3. Physical damage to structures and life hazard. IEC 2006; p. 164.

[8] Kurita H. Lightning protection of persons on structures, Proceedings of 5th Asia lightning protection forum, Jeju Korea, April 2008; pp. 113-2

[9] Gorin BN, Shkilev AV. Measurements of lightning currents at the Ostankino tower. Elektrich 1984; 4: 64-5.

[10] Fuchs F. On the transient behavior of the telecommunication tower at the mountain Hoher Peissenberg. Proceedings of the $24^{\text {th }}$ International conference on lightning protection. Birmingham 1998; pp. 36-41.

[11] Rakov VA. Transient response of a tall object to lightning. IEEE Trans EMC. 2001; 43: 654-61.

[12] Hussein A, Janischewskyj W, Milewski M, et al. Chisholm, Returnstroke current waveform parameters of lightning to the $\mathrm{CN}$ Tower (1992-2001). Proceedings of the $26^{\text {th }}$ International confe-rence on lightning protection, Cracow, Poland 2002; pp. 161-6.

[13] Zischank W, Kern A, Frentzel R, Heidler F, Seevers M. Assessment of the lightning transient coupling to control cables interconnecting structures in large industrial facilities and power plants. Proceedings of the $25^{\text {th }}$ International conference on lightning protection. Rhodes, Greece. Sep 2000; pp. 691-6. 